\title{
THE TREATMENT NEEDS OF VICTIMS/SURVIVORS OF CHILD SEXUAL ABUSE (CSA) FROM ETHNIC MINORITY COMMUNITIES: A LITERATURE REVIEW AND SUGGESTIONS FOR PRACTICE
}

\section{Pooja Sawrikar and Ilan Katz}

Corresponding author Dr Pooja Sawrikar, School of Human Services and Social Work (HSV), Griffith University (GU), Gold Coast campus, Parklands Drive, Southport, Queensland, 4222, Australia, p.sawrikar@griffith.edu.au

Co-author Professor Ilan Katz, Social Policy Research Centre (SPRC), University of New South Wales (UNSW), Australia, ilan.katz@unsw.edu.au

Highlights • This exhaustive literature review is a significant contribution to knowledge • Protecting family name is a significant barrier to help-seeking among minorities • It may even heighten risk of suicidality among minority victims of CSA • Treatment must be culturally competent else it may further abuse of power

Disclaimer This manuscript has not been published elsewhere, and is not under consideration by any other journal. However, this article reports on the findings from one of six themes explored in a larger study. Thus, content in the Introduction and Method overlaps with content in articles currently under consideration with other journals but which then report on the findings from one of the other explored themes, making them each overall different from one another.

Acknowledgments We would like to thank Professor Fiona Arney, Professor Leah Bromfield, Dr Jen Hamer, and Professor Patrick O'Leary for their comments and feedback on an earlier version. We would also like to thank the anonymous reviewers of this article for their comments and feedback, which have been incorporated into the manuscript.

Conflict of interest There is no known conflict of interest. 


\title{
THE TREATMENT NEEDS OF VICTIMS/SURVIVORS OF CHILD SEXUAL ABUSE (CSA) FROM \\ ETHNIC MINORITY COMMUNITIES: A LITERATURE REVIEW AND SUGGESTIONS FOR \\ PRACTICE
}

\begin{abstract}
One significant finding from an exhaustive literature review on child sexual abuse (CSA) and ethnic minority communities is that victims appear to be at higher risk for suicidality. This may be due to the many barriers to professional help-seeking in this group, most commonly associated with protecting the family's name. This makes their treatment needs particularly critical, after the barriers have finally been crossed. Of all their treatment needs, cultural competency is identified as essential. It asks for non-racist attitudes and practice, selfreflection and awareness, a 'multicultural framework' which recognises differences in power between mainstream and minority groups and respects the right to cultural differences, the provision of an interpreter trained in matters to do with sexual assault, choice about having an ethnically-matched or non-matched service provider (and thus employment of workers from diverse backgrounds), the routine provision of training in cultural competency by management in service organisations, and mandatory data collection on variables related to ethnicity. A 'multicultural framework' is seen to be the most important of these elements, else it could lead to the vilification of collectivist and patriarchal cultures (which ethnic minority communities tend to be), threatening cultural safety. This adds trauma to the victim who has already suffered an abuse of power, and further alienates clients in critical need of clinical intervention.
\end{abstract}

\section{Keywords}

Child sexual abuse (CSA), ethnic minorities, treatment, service delivery, cultural competency, cultural safety 


\section{THE TREATMENT NEEDS OF VICTIMS/SURVIVORS OF CHILD SEXUAL ABUSE (CSA) FROM ETHNIC MINORITY COMMUNITIES: A LITERATURE REVIEW AND SUGGESTIONS FOR PRACTICE}

\section{$1 \quad$ Introduction}

\subsection{Background: Why this literature review was conducted}

The literature on child sexual abuse (CSA) and ethnic minorities is substantially under-developed (Korbin, 2002; Miller \& Cross, 2006; Thoburn, Chand, \& Procter, 2005; Welbourne, 2002), especially in Australia (Bromfield \& Arney, 2008; Burke \& Paxman, 2008; Cashmore, Higgins, Bromfield, \& Scott, 2006; Sawrikar, 2017) where there is only one such identifiable empirical study (Taylor \& Norma, 2013). The risk of not having this kind of knowledge is that victims/survivors from ethnic minority communities may be received into the clinical setting as if their experiences until then have been the same, and then receive the same kind of treatment, as their mainstream counterparts.

However, the social services sector is fully aware that a 'one-size-fits-all' model is a threat to good practice (Ahmad, Driver, McNally, \& Stewart, 2009). This awareness does not match the paucity of national research; over $31 \%$ of Australia's population are first and second generation from non-English speaking countries (Australian Bureau of Statistics [ABS], 2012-13), yet there remains virtually no research on the nexus of CSA and multiculturalism. This gap in knowledge reflects two broader issues in the Australian context (which cannot be discussed here in length for brevity).

The first is that Australia has a political or structural-level history of expecting migrants to assimilate (the 'White Australia policy'). This carries a whole raft of other issues such as the belief that the mainstream culture is better and/or that cultures of origin should submit theirs to the majority since they are joining the new country. Even when migrants choose to migrate (unlike refugees and asylum seekers) they face an impossible challenge: that they cannot (pretend to) be someone they are not (Sawrikar, 2017). It is for this same reason that Anglo Australians have not assimilated into Indigenous culture when they migrated. Even when migrants do attempt to assimilate, they meet limitations. Visible differences such as skin colour, religious attire, and accents keep them out of the 'in-group' (Tajfel \& Turner, 1979). This history continues presently with supporters of right-wing political parties, both nationally and internationally. 
The second issue is that Australia's Stolen Generations and the 'Northern Territory [NT] intervention' have clearly revealed the racism that exists in the child protection system, with Aboriginal children respectively being 'protected' from assumptions of poor (i.e. non-white) parenting and risk of sexual abuse and family violence being higher than in the mainstream community (Sawrikar, 2017). Governments are now cautious to ensure they do not repeat history's mistakes with other non-mainstream families (i.e. ethnic minorities), but this plays out in the form of a poor research agenda in the area.

To address the current gap in knowledge, and not further perpetuate threat to child safety in the form of silence, an exhaustive literature review on CSA and ethnic minorities in Australia was conducted. The review explored six themes: (i) community awareness of CSA, (ii) preventing CSA, (iii) encouraging disclosure of CSA, (iv) the treatment needs of victims/survivors of CSA, (v) possible service delivery models for Australia, and (vi) current national service provision to victims/survivors.

This article reports the findings of theme four - treatment needs (the others are reported elsewhere). Specifically, it addresses three research questions: (1) what are all the barriers to professional help-seeking among victims/survivors of CSA from ethnic minority communities? (2) what are all the risks to mental wellbeing as a result of the abuse? and (3) what are all the needs of victims/survivors once they have entered the clinical setting? In doing so, this review makes a significant contribution to knowledge as it helps ensure that service delivery is tailored to best meet the needs of victims/survivors of CSA from ethnic minority communities in multicultural countries like Australia.

\subsection{The client group: Defining 'ethnic minorities' in more detail}

Ethnic minority communities are those that have a migration history and are minorities in at least one of the four main dimensions of ethnicity identified by O’Hagan (1999) - race, language, culture, and religion. Thus, they are differentiated from their Indigenous (Aboriginal and Torres Strait Islander) and Anglo (Saxon and Celtic) Australian counterparts, generally come from non-English speaking backgrounds (NESBs), and tend to originate from countries higher on collectivism (see below for more information). The term usually includes refugees and asylum seekers, but their needs and experiences are even more specific than the larger group (Allimant \& Ostapiej-Piatkowski, 2011). The term 'culturally and linguistically diverse' (CALD) used in the Australian research and policy discourse has not been used here because it only highlights issues to do with culture and language rather than racial and religious factors also (Sawrikar \& Katz, 2009). 
As stated earlier, ethnic minorities tend to originate from countries higher on collectivism than Western countries like Australia, the US, UK, Canada, and New Zealand, which remains pertinent after migration because cultural norms, values, and traditions do not simply disappear into a 'melting pot', as the extensive literature on acculturation shows. The seminal researcher Berry (1980) highlights that migrants continuously manage two conflicting needs - the need to preserve the culture of origin and the need to adapt to the new culture - in response to a number of variables. For example, acculturation is affected by whether the person speaks their native language, their generational status, their developmental age, whether they are visibly different to the mainstream, whether they experience racism and discrimination, the local area where they reside, and national and international political discourse (Sawrikar \& Katz, 2010; Sawrikar \& Katz, 2009; Sawrikar \& Hunt, 2005). Thus, acculturation is a dynamic process, and extends to even well-established migrant groups and across generations.

To more clearly define the term, 'collectivism' is a cultural stance that sees the basic unit of society to be the family, and it is differentiated from 'individualism' which sees the individual to be the basic unit of society (Hofstede, 1980). More specifically, collective cultures value social order, harmony, support and roles; the family provides security in exchange for loyalty and obedience; inequality (usually based on age and gender) is seen as appropriate and acceptable; and members tend to be more homogenous as deviations from the norm are not tolerated as greatly (Bond, 2002; Triandis, 1990). In contrast, individualistic cultures value independence, autonomy, initiative and uniqueness; emphasise that individuals have the right and responsibility to look after themselves; stress horizontal relationships based on equality; and tolerate deviations from the norm to a greater extent (Bond, 2002; Triandis, 1990).

According to the seminal work of Hofstede (2001), the US, Australia, UK, Canada, and New Zealand, all rank (in order) highest on individualism. Western European countries rank next highest, and the remaining parts of the world (e.g. East Europe, Asia, South America, Middle East, Sub-Saharan African, etc.) all rank more highly on collectivism. The implication is that many ethnic minorities in Western countries high on individualism originate from non-Western countries high on collectivism.

The theoretical framework of individualism/collectivism is useful here because collectivist cultures place greater value for family and community over the needs of individuals. In the context of CSA, the needs of victims may be de-prioritised to the needs of the family, most especially the need to protect the family's 'face' or reputation. Collectivist cultures also overtly accept gender inequalities, making the association between collectivism and 
patriarchy also overt. As the father is seen to be the head of the family, has most of the power within the family, and in turn is most associated with the family's 'face' or reputation, allegations of CSA against fathers or other senior males in collectivist cultures are perceived as accusations against the whole family, so in order to save 'face' it is often the accuser and/or victim that is excluded by the family rather than the alleged abuser.

Importantly, the theoretical framework is not being used to minimise the importance of family, reputation, patriarchy, silence, and exclusion among individualistic groups (which does occur), but to highlight their centrality among collectivist ones. This is necessary when attempting to identify how best to protect children from these communities; it provides a culturally relevant 'lens' for making sense of their needs and experiences. In short, patterns of silence and exclusion to protect reputation occur in collectivist cultures, but are not exclusive to them.

Although the theoretical framework is seen as critical for understanding the daily lived experiences and social structures of, and therefore CSA in, ethnic minority communities, it is still important to point out that individualism and collectivism are just generalised stereotypes. This occurs because cultures tend to be heuristically categorised as one or the other, whereas in fact all cultures exist on a continuum of individualism and collectivism. Thus, these groupings should not be definitively relied on; they need to be used with vigilance, ensuring that the beliefs comprising the stereotypes are accurate, do not perpetuate harm or disadvantage to groups, and are questioned when applied to individual situations (Sawrikar, 2017). This is particularly critical for clinical practice because stereotyped assumptions about culture can result in inappropriate and even harmful outcomes (Owusu-Bempah \& Howitt, 2000).

In short, the broad or macro-level conceptualisation of culture used here - the dichotomy between individualism and collectivism - is necessary but not sufficient for understanding CSA among ethnic minority communities. Each group will have its own cultural norms, values, and traditions about CSA, demanding more nuanced attention to detail.

\section{$2 \quad$ Method}

\subsection{Approach}

The methodology for obtaining the literature that addressed the six themes of the larger study was informed by the Preferred Reporting Items for Systematic Reviews and Meta-Analyses (PRISMA) process. Figure 1 summarises the PRISMA flow diagram (Moher, Liberati, Tetzlaff, \& Altman, 2009). 
Literature was first sourced from a number of relevant databases - Australian Public Affairs Full-Text, Health and Society Database, Informit Family and Society Collection, Informit Health Collection, Informit Humanities and Social Sciences Collection, Multicultural Australia and Immigration Studies, ProQuest Family Health, PsycINFO, Scopus, Social Services Abstracts, and Sociological Abstracts.

Search terms related to the two keywords - 'child sexual abuse' and 'ethnic minorities' - were then combined. Search terms related to the first keyword were: sexual abuse, sexual harassment, sexual exploitation, molestation, rape, indecent assault, sexual violence, and gender violence. Search terms related to the second keyword were: culture (cultur*), race (rac*), culturally and linguistically diverse (CALD), non-English speaking background (NESB), ethnic minority/ies (ethni*), migrant, immigrant, refugee, asylum seeker, of color/colour, and community.

Literature was then limited to 2000-2016 to ensure it was recent (but it did not exclude seminal research, sourced from the reference lists of the newer articles), as well as to only articles in English, peer-reviewed, and with the full-text available. Only literature specifically related to sexual abuse experienced in childhood by someone from an ethnic minority background (i.e. ethnic minorities in Western countries or about non-Western countries) was included.

To address a priori issues to do with the transferability of findings from Indigenous groups in other Western countries and/or minority groups not represented in Australia, literature was then excluded if it only pertained to Native Americans and African Americans. Literature only pertaining to Latina/Hispanic Americans was also excluded on the grounds that they form a large and significant minority group in the US and so their needs and experiences could be quite specific to that context. However, literature that addressed groups in addition to Native, African, and Latina/Hispanic Americans - for example, Asian-Americans - were included in the review, so the former groups have not been wholly disregarded.

Applying these criteria left a total of 135 records eligible for full review. Of these, 42 primarily used qualitative methodologies, 65 primarily used quantitative methodologies (including meta-analyses), eight used a mixedmethods approach (counted under the 'Quantitative' records), and 28 used secondary analyses (e.g. literature reviews, commentaries, etc.). As the secondary analysis records did not use either qualitative or quantitative methodologies, they do not appear in the flowchart. Other literature, mostly on child maltreatment and ethnic minority communities more broadly (rather than CSA specifically) as well as family violence and ethnic minority communities, was also drawn on where relevant. Only the articles relevant to the aims of this article - 
establishing the importance, and identifying the characteristics, of the treatment needs of victims/survivors from ethnic minority communities - have been cited here. To assist readers with identifying the characteristics, aims and methodology of the articles obtained from the PRISMA process, a summary has been provided in the Appendix. [Note: for brevity, this table only contains articles that focus on CSA rather than child maltreatment more broadly or family violence in adult samples, even though themes in these three bodies of literature overlap].

Figure 1: PRISMA flow diagram

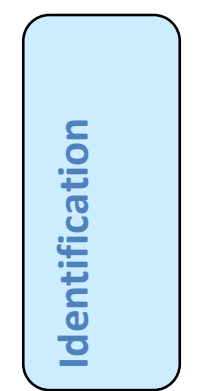

Records identified through database searching $(n=9,560)$
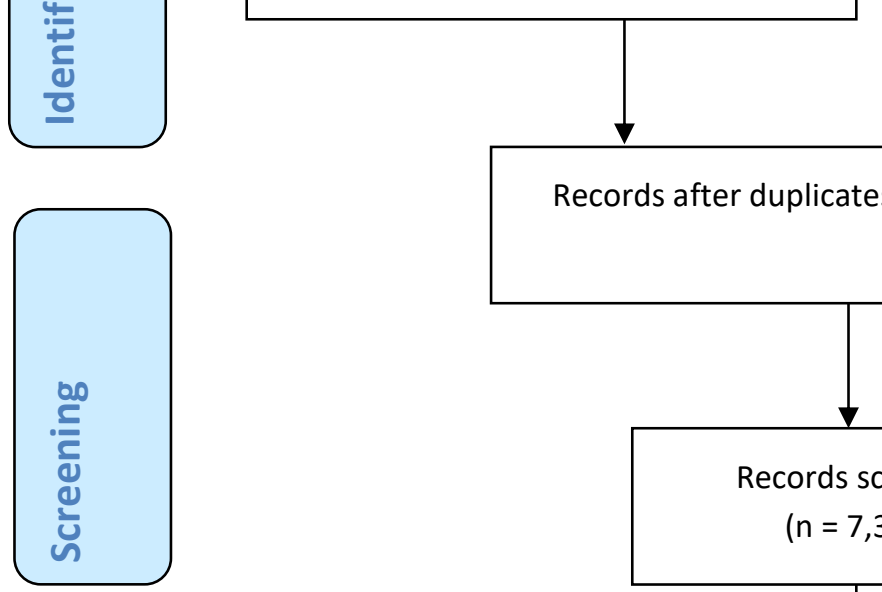

Records after duplicates removed $(n=7,363$ )
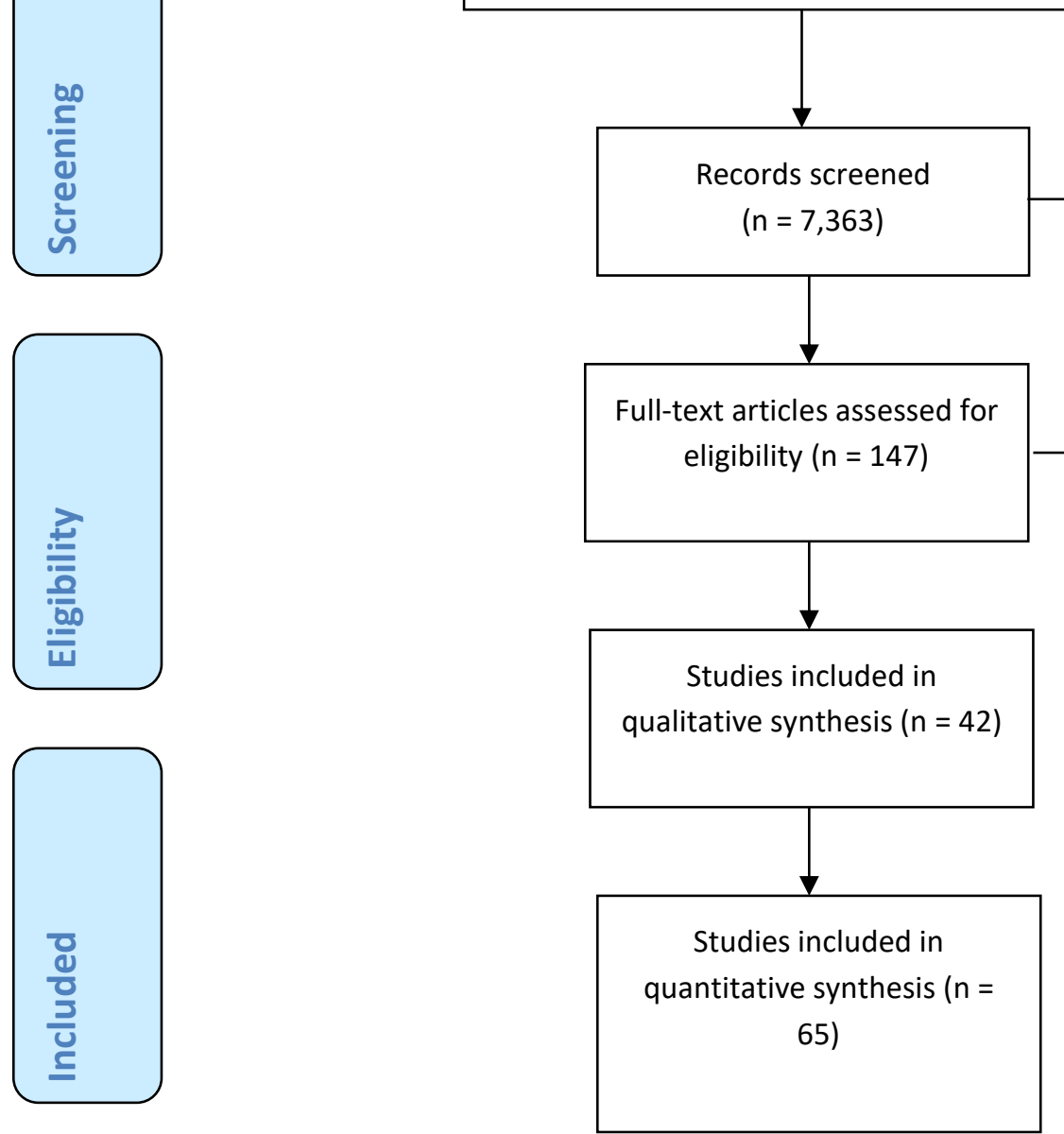

Additional records identified through other sources $(n=0)$

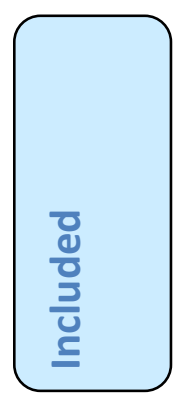




\subsection{Strengths and weaknesses}

The approach for obtaining the literature was systematic, comprehensive, and exhaustive. The results have also been reported by describing all literature (within word limits) related to each identified theme. Nevertheless, there are methodological limitations that need to be acknowledged.

The first is that the body of literature is small, as already noted. Still, several researchers note that literature from Western contexts should not be used to make sense of the needs and experiences of ethnic minorities (Baker, Gleason, Naai, Mitchell, \& Trecker, 2013; Chen \& Chen, 2005; Chien, 2013; Elbedour et al., 2006; Gilligan \& Akhtar, 2005; Mildred \& Plummer, 2009; Reavey et al, 2006; Sil \& Soo, 2008; Wang \& Heppner, 2011; Usta \& Farver, 2010).

Another limitation is that the review has grouped several different races, cultures, languages, and religions together, falsely homogenising each of their needs. Fontes (1993) calls this 'ethnic lumping'. It usually occurs because of small sample sizes in research for each group comprising the larger category. There is some merit in this - minorities share some experiences such as language barriers, racism and discrimination, and a collectivist background - making results from one group reasonably generalisable to another. Also, the inclusion of articles from diverse backgrounds is a global approach consistent with and required for issues that address multiculturalism. The approach however falls short at the more nuanced and detailed level of culture, language, and religion; traditions, beliefs, norms, and values about CSA within one group will not necessarily transfer to another. These limitations must be acknowledged, and addressed where possible, as part of ethical conduct in research

Another limitation is that almost all of the literature is about minority groups in other Western countries, most especially the US and UK, posing issues for the transferability of findings to the Australian context. This issue was somewhat addressed by excluding literature that related solely to groups not represented in Australia (e.g. Native and African Americans), however caution still needs to be exercised. Reasonable comparisons can be made with countries like the US, UK, Canada, and New Zealand, however they do have different 'ethnic profiles' to Australia, with different specific groups and sizes comprising their migrant community, as well as reasons for their migration to these countries, which all affect their socio-cultural and political standing there (Sawrikar \& Katz, 2008). Overall, the paucity in Australian research meant that the review necessarily had to borrow from overseas to help inform the national context. 
Finally, there is the issue that themes identified in the literature from non-Western countries of origin only partially help explain the needs and experiences of ethnic minorities in Western countries because the migration experience interacts with cultural factors in such a unique way that literature from 'back home' becomes limited or even irrelevant. Moreover, literature from non-Western countries of origin was not equally represented; most was about East Asians and South Asians, sub-Saharan and South Africans, and Arabs and Jews, so the experiences of other groups are even less well documented.

Notwithstanding these limitations, this review has exhausted all themes identified in the literature on the treatment needs of victims/survivors of CSA among ethnic minority communities. These themes are described below in the form of a narrative review and therefore thematic analysis is merged with description.

\section{$3 \quad$ Results}

The results of the review indicate that there are many barriers to professional help-seeking. The most significant is the need to protect the family's name or reputation. It also appears that victims from minority groups are at higher risk of suicidality. Arguably, the need to protect the family's name leads to delays in seeking clinical support, which in turn heighten the symptoms of mental illness that have resulted from traumatisation.

Such a link requires rigorous empirical investigation in the future, because the currently small body of knowledge cannot yet support this. Nevertheless, the literature on (i) barriers to help-seeking, (ii) risks to mental well-being as a result of abuse, and (iii) the needs of victims once they have entered the clinical setting, (currently treated as disparate and in need of investigation for causal association), are all described in more detail below.

\subsection{Barriers to help-seeking}

Several barriers to professional help-seeking in ethnic minority communities were identified. Some of these are cultural in nature and some are not, and others are not cultural but occur only for ethnic minority communities. Thus, this article offers a new three-tiered approach to the categorisation of barriers for ethnic minorities: (i) non-cultural, (ii) acculturative (or migratory), and (iii) cultural. This is particularly important for ensuring that not all issues for ethnic minorities are falsely seen as 'cultural' or inherently belonging to the group.

\subsubsection{Non-cultural barriers}

\subsubsection{Lack of awareness of services}


Allimant and Ostapiej-Piatkowski (2011) report that "despite extensive community education, women from culturally and linguistically diverse backgrounds who access Immigrant Women's Support Service (IWSS) in Brisbane are not familiar with [their] Sexual Assault Program" (p. 9). However, they also go on to say that this is "not unusual or surprising because people generally do not pay much attention to information about services in their local community unless there is a possible need for them or someone they know" (p. 9). Thus, lack of awareness of services in the local community present as a barrier to their uptake (Sawrikar \& Katz, 2008) for all groups. Importantly, lack of awareness among ethnic minority communities may relate to other factors as well, such as language barriers and shame for seeking extra-familial support. Thus, this barrier does not work in isolation, and so is not wholly a 'non-cultural barrier'

\subsubsection{Lack of worthiness and wanting to forget}

As with all victims of CSA, those from an ethnic minority community may not seek help because they do not see themselves as deserving. This may be due to low self esteem (Taylor \& Norma, 2013) or because "they blame themselves for being a victim as a result of power inequality between men and women, (so) do not feel empowered to seek help" (Smith, Bryant-Davis, Tillman, \& Marks, 2010, p. 262). Note: Most victims are female perpetrated by males, at reported ratios of 3:1 in some studies (Chen, Dunne, \& Han, 2004; Wang \& Heppner, 2011) and 4:1 in others (Krug, Dahlberg, Mercy, Zwi, \& Lozano, 2002; Thornton \& Veenema, 2015). There may also be "resistance to the therapeutic process for fear of being 'taken back' to events they want to 'forget'. Caretakers (may also) want the child to forget about the rape, move on, and not talk about (it)" (Mathews, Abrahams, \& Jewkes, 2013, p. 651). Thus, lack of worthiness and wanting to forget are non-cultural barriers to seeking professional help.

\subsubsection{Acculturative/migratory barriers}

\subsubsection{Fear of deportation}

Another barrier to professional help-seeking among victims from ethnic minority communities may be fear of deportation. As an example, Singh (2009) says "(South Asian) women (in the US) experienced tension when using mental health services while being identified as an immigrant for fear that reporting intimate partner violence would endanger their immigration status. This fear is manifested as silence about the violence women experienced" (p. 364-5). This fear is also reported in minority samples in Australia (Allimant \& OstapiejPiatkowski, 2011; Taylor \& Putt, 2007). Importantly, this barrier is not a 'cultural' issue because it does not 
pertain to collectivist values. Instead, it is a 'migratory' issue; it occurs for ethnic minority communities but only as a result of the migration process. Thus, it is not a factor that 'belongs' to ethnic minority communities in the way cultural values do (Sawrikar, 2017), it simply occurs for them.

\subsubsection{Language barriers}

Some "immigrants may lack access to bilingual services, so there is an underreporting of abuse resulting from language barriers" (Kenny \& McEachern, 2000, p. 909). Again, this barrier is not 'cultural' but 'migratory', as it occurs for ethnic minority communities only after migration. It also highlights the necessity for bilingual staff and interpreters (see '3.3.1.2 Interpreters' for more information).

\subsubsection{Cultural barriers}

\subsubsection{Fatalistic and/or religious beliefs}

"Some groups (such as Arab Americans) may not utilise mental health services because of the fatalism inherent in the religious belief that God is the "cause of all that is"” (Haboush \& Alyan, 2013,p. 511). Kanukollu and Mahalingam (2011) also say, "with more fatalistic viewpoints of the world and certain core spiritual beliefs like karma (fate and destiny) and dharma (right-action) in Hinduism, some South Asians may not opt to seek help but rely on spirituality instead" (p. 230). Thus, fatalistic and/or religious beliefs may prevent some victims from seeking help.

\subsubsection{Normative reliance on intra-familial support}

One particularly important cultural barrier to professional help-seeking is that family is the main source of support in collectivist cultures, so extra-familial support is not normatively sought (Back et al., 2003; Gilligan \& Akhtar, 2005; Kenny \& McEachern, 2000; Samms \& Cholewa, 2014). As Nesci (2006) puts it, “for many communities where the individual looks to the extended family and community for help when there is a problem, the idea of seeking help from strangers is a strange and bewildering concept" (p. 44).

Elbedour, Abu-Bader, Onwuegbuzie, Abu-Rabia, and El-Aassam (2006) found that "although Bedouin-Arab female respondents reported fear and worry as a result of their (sexual) violations, $43.5 \%$ reported seeking help from nonprofessional counselors (e.g. family members, friends, teachers) to help them cope with their abusive experiences. This suggests, encouragingly, that for a significant proportion of adolescents, the shame and stigma associated with sexual abuse are not so completely debilitating that these experiences cannot even be 
mentioned" (p. 226). Critically, the finding also demonstrates how family is the primary source of support in collectivist groups.

Kanukollu and Mahalingam (2011) also say, "many individuals from non-Western cultures have the impression that therapists are equivalent to gurus, benefactors, or guides who disseminate advice. For the (South) Asian client, social etiquette of formal hierarchical expectations (related to age and gender) is of utmost importance. This equates to showing deference, respect, and obedience to the superior as well as keeping disagreements and any negative feelings to themselves. The subordinate, the Asian client, expects the superior (the therapist) to be responsible and nurturing in exchange for this deference, maintaining and enhancing the esteem of the other. With this role already fulfilled by figures within the community like elders in the family or family gurus, South Asians might not feel the need to seek mental health services" (p. 230).

Moreover, "(South Asian) individuals may not match the individualistic basis of many Western therapies, which contrasts with Eastern values placed on family interdependence. Psychotherapy almost always involves individual examination, often pulling for insight, self-disclosure, and verbal/emotional expressiveness. This is in contrast to South Asian values influenced by social and religious systems that underscore the well-being of the whole and affective control” (Kanukollu \& Mahalingam, 2011, p. 230).

\subsubsection{Shame for seeking extra-familial support}

Another critical cultural barrier is that seeking professional help is stigmatically seen as a sign of weakness and therefore shameful (Elbedour et al., 2006; Futa, Hsu, \& Hansen, 2001; Samms \& Cholewa, 2014). This occurs in Western/individualistic samples also and so is not a cultural barrier exclusive to ethnic minority communities. However, "due to the collective orientation of (minority groups like) Asian Americans, the stigma and shame reflecting on an individual (for seeking help against the) values for self-control, suffering, and persevering in the face of adversity, also reflects stigma and shame on all members of the family" (Futa et al., 2001, p. 199).

Consistent with this, Allimant and Ostapiej-Piatkowski (2011) report that CALD women clients they have worked with have "commented they would "rather be killed" than have their experiences and contact with a sexual assault service disclosed publicly in the community. (Thus), some may feel they have no choice but to remain silent” (p. 9). In the literature on intimate partner violence (IPV), Ahmad et al. (2009) similarly say, "loss of face (among South Asian women victims in Canada) could be crippling ... one participant called the social stigma for partner abuse and divorce a "cancer" reflecting its chronic and complex nature with 
perceptions of (it) being non-curable and life threatening” (p. 619). In a study by Reavey, Ahmed, and Majumdar (2006), "some (professionals in the UK) held the view that cultural 'enmeshment' prevented some South Asian women from using services, because they did not relate to even the basic belief that they, as an individual, needed and deserved help from a service, resulting in a suppression of negative feelings associated with the abuse, (and in turn, an) increase in the risk of mental health problems" (p. 180).

\subsection{Risks to well-being}

\subsubsection{Without consideration of culture}

The unfortunately long list of negative effects of CSA on physical and psychological well-being is well established in the literature. Summarily, they can include: poor academic performance, interpersonal problems (e.g. withdrawing from friends and family), low self-esteem, sexual risk taking behavior, promiscuity, prostitution, unwanted pregnancy, illegal abortions, STDs, HIV/AIDS infections, sexual dysfunction, cigarette smoking, substance abuse, anger control problems, aggression, truancy, running away, delinquency, criminality, bestiality, depression, anxiety, post traumatic stress disorder (PTSD; marked by flashbacks, intrusive memories, nightmares, and negative thoughts), eating disorders, sleeping disorders, disassociation, borderline personality disorder, cynical thinking about the world, themselves, and others, nonsuicidal self-injury (NSSI), and suicidality (Capri, 2013; Chen et al., 2004; Freeman \& Temple, 2010; Gibson, Emeka, \& Walters, 2007; Jewkes, Dunkle, Nduna, Jama, \& Puren, 2010; Laungani, 2003; Li, Ahmed, \& Zabin, 2012; Ma \& Li, 2014; Mansbach-Kleinfeld, Ifrah, Apter, \& Farbstein, 2015; Marie, Fergusson, \& Boden, 2009; Mathews et al., 2013; Meade et al., 2012; Nagata et al., 2001; Richter et al., 2014; Sil \& Soo, 2008; Ullman \& Filipas, 2005; Weierich \& Nock, 2008; Zhang et al., 2013).

Victims are also at greater risk of being re-victimised (Freeman \& Temple, 2010; Mathews et al., 2013). For example, in a study in Papua New Guinea, one participant said, "because I was raped before, he thinks that I am that type who can have sex with anyone" (Lewis, 2012, p. 282). As Russell (1986) puts it, “once a woman is labelled promiscuous, her right to refuse sex is frequently denied" (cited in Capri, 2013, p. 36). Barnes, Noll, Putnam, and Trickett (2009) found that female victims of CSA were 1.99 times more likely than females who had not experienced CSA to be sexually re-victimised as adults” (cited in Santos-Iglesias \& Sierra, 2012, p. 3469). 
There is "a growing consensus that the most serious health consequences arise when the sexual abuse is penetrative, protracted, and occurs at a young age" (Chen et al., 2004, p. 1172). The research shows that "the odds ratios of depression, anxiety, and suicidal ideation are higher among people with contact CSA than those with noncontact CSA" (Li et al., 2012, p. S48). Lev-Wiesel and Amir (2005) also report that "the age at which rape and/or sexual molestation occurs is critical. Sexual abuse at a young age is likely to result in more severe forms of PTSD, and extremely low self-esteem, self-hatred, and self-blame are common” (p. 73).

Symptoms of mental illness also seem to be worse when the perpetrator is known. For example, Haj-Yahia and Tamish (2001) found that "significantly higher psychological symptoms were reported by victims (in Palestine) who had been abused by a family member than by those who had been abused by a non-family individual" (cited in Usta \& Farver, 2010, p. 366). If coupled with insecure attachment environments, these are particularly deleterious to a victim's health trajectory. For example, Capri (2013) says, "there is a documented link between a history of CSA, an insecure attachment environment, and borderline personality disorder in psychiatric patients ... and impaired parent-child relationships coupled with CSA are predictive of suicidal behaviour in children and adolescents. Neuropsychological findings suggest that the trauma of CSA, in the absence of a buffering and ameliorating secure attachment, may have lasting neurological sequelae" (p. 35-6). Ma and Li (2014) similarly report that if the perpetrator is intra-familial, then the risk of disorganised/insecure attachment, leading to poor self-emotional regulation, is also high.

Contrary to this, however, Lev-Wiesel and Amir (2005) found (in a literature review on child survivors of the Holocaust who were sexually abused during World War II) that "life was perceived as worthless by $76 \%$ of the participants (in their study), in spite of reporting the existence of a warm, supportive, loving family and being economically well-established. Thus, (their results show that) regardless of the identity of the perpetrator, the sexual abuse trauma affects survivors' ability to enjoy life ... (Indeed), most women designate sexual abuse as the worst traumatic event they could experience" (p. 73, 79).

Overall, "sexual abuse leads to both immediate distress and long-term effects for the victim" (Kenny \& McEachern, 2000, p. 911). "Some children may not report any psychological distress because they are afraid to express their true emotions or may deny their feelings, and other children may have 'sleeper effects' (Petty, Wegener, Fabrigar, Priester, \& Cacioppo, 1993), where they experience no harm in the short run but suffer severe problems later in life" (Karthiga \& Ravikumar, 2014, p. 728). 
Indeed, Taylor and Norma (2013) critically point out that "families can misunderstand delayed disclosure as somehow indicating successful 'recovery' and a cultivated ability to cope with the crime sufficiently enough to open up about it. Consequently, they may expect the victim "to have gotten over it by now". Families may not understand that a victim's recovery may be wholly unrelated to their motivation for disclosing sexual assault, and survivors may disclose to family members precisely at a time when they find themselves no longer able to cope with the memory and feelings of victimisation" (p. 118).

It is for this reason that $\mathrm{Li}$ et al. (2012) also make a call to professionals to investigate a possible history of CSA when they are in treatment for psychological outcomes of CSA but are unaware of the link. They say, "knowledge about the long-term effects of CSA should be promoted so that adults can advocate for themselves and obtain treatment for childhood traumas" (p. S50).

In short, risks to well-being can be extensive and severe, and occur in both the short- and long-term. However, it appears that these risks are amplified for victims/survivors from ethnic minority communities because of collectivist values for the family name, which may then be associated with avoidance coping and self-blame, heightening the risk of suicidality, and maintained by patriarchal structures.

3.2.2 With consideration of culture: Protecting the family name, avoidance coping, self-blame, patriarchy, and suicidality

"Some children display almost no PTSD symptoms following their sexual assault, and the degree to which an individual is affected is mediated by a number of factors (such as) maternal support following abuse, peer network, and pre-existing psychopathology" (Kenny \& McEachern, 2000, p. 911-12). However, Phasha (2010) notes that "the meaning or interpretation that an individual attaches to the abuse contributes significantly to his or her recovery from a traumatic event. In particular, an individual who does not blame himself or herself for the occurrence of the abuse or fate is capable of recovering quickly because he or she can claim back his or her personal power to function better than those who are overwhelmed with self-blaming attitudes" (p. 1247). Thus, internal coping strategies (Kenny \& McEachern, 2000) and external attributions (Ullman \& Filipas, 2005) appear to have the capacity of mediating risk factors to well-being.

Unfortunately, however, there appears to be widespread use of avoidance coping among ethnic minority communities (Barker-Collo, Read, \& Cowie, 2012; Chien, 2008; Kenny \& McEachern, 2000; Ullman \& Filipas, 2005). It may be that such avoidance coping strategies (e.g. dissociation) are used because the pressure to 
protect the family, over the individual, leaves them with little choice. As Singh (2009) points out, "when a (South Asian) woman's silence is demanded, according to cultural values that attempt to maintain family cohesion and minimise discord between the private and public domains of her life, this silence may encourage the development of long-term trauma symptomology that damages her daily functioning in a negative manner" (p. 363, 370).

Consistent with this, Libby, Orton, Novins, Beals, and Manson (2005) showed that "in two American Indian tribes, Southwest and Northern Plains, child sexual abuse was associated with PTSD for both tribes, but only in the Southwest was it significantly associated with depression and anxiety (as well). The authors proposed that these tribal differences may be attributed to cultural differences. Compared with Northern Plains, the Southwest has higher degrees of social integration and control" (cited in Li et al., 2012, p. S46).

Luo (1987) also reports that "Asian female rape victims in Hawai'i suffered greater trauma than their Caucasian counterparts particularly in the areas of helplessness, shame, embarrassment, and concern about family and/or others' reactions" (cited in Luo, 2000, p. 582).

Finally, Tang (2009) conducted a large quantitative study $(n=1,240)$ that explored the role of gender and ethnicity (specifically Asian and Pacific Islander populations in America) in PTSD. They found that higher concerns with loss of face were associated with increased symptoms of PTSD (cited in Foynes, Platt, Hall, \& Freyd, 2014, p. 135).

Research shows that the overall rate of suicidality of people from ethnic minority communities is lower than that of other Australians. ${ }^{1}$ However, this is different to the research that has been reviewed here, specific to CSA and suicidality, which suggests that minorities fare worse in relation to risk for suicidality.

In a small quantitative study ( $\mathrm{n}=153)$ Back et al. (2003) report that "child sexual abuse survivors in Singapore had elevated (psychological) symptom levels on the widely used and rigorous Symptom Checklist-90-Revised [SCL-90-R; Derogatis, 1983] relative to survivors in the US” (p. 1270). Rao et al. (1992) conducted a relatively large-scale quantitative case file review of 98 Asian, 80 Black, 80 White, and 80 Hispanic abuse children that were randomly selected, and also "found that Asian-Americans who were abused were least likely to display inappropriate sexual behaviours and anger, when compared to whites and blacks, but were often suicidal" (cited

\footnotetext{
${ }^{1}$ http://www.mindframe-media.info/for-media/reporting-suicide/priority-population-groups/culturally-and-
} $\underline{\text { linguistically-diverse-populations }}$ 
in Kenny \& McEachern, 2000, p. 912). Reavey et al. (2006) say, "recent government sponsored community research, carried out in Manchester UK, has identified sexual abuse and domestic violence as common factors which contribute to poor mental health, suicide, and self-harming among young South Asian women” (p. 173). “A study in Ethiopia (conducted by Worku, Gebremariam and Jayalakshmi (2006) with a sample of 323 female students in Grade 9) shows a high rate of negative psychological effects, such as suicide ideation, suicide attempt, and sexual dysfunction, among people with an experience of child sexual abuse" (cited in Li et al., 2012, p. S45). Finally, “Tutken (1996) reports a suicide attempt rate of 64\% (in a Turkish sample) with a dissociative disorder and a recorded history of child sexual abuse ... (despite) 'religiosity' and prohibitions against suicide being frequently referred to as protective factors" (cited in Stewart, 2005, p. 9, 11).

In addition to avoidance coping, the research shows that self-blame can also lead to worse outcomes. This is not exclusive to minority groups. For example, Feiring, Coates, and Taska (2001) explored ethnic status, stigmatisation, support, and symptom development following sexual abuse in 130 children from African American, European American, and Hispanic families and found that "White children reported more internal attributions of blame than Hispanic children" (cited in Ullman \& Filipas, 2005, p. 70). Based on this finding, they assert that "European American families may socialise their children to emphasise individual control that (can also) heighten their self-blame" (Ullman \& Filipas, 2005, p. 84).

However, widespread acceptance of myths about CSA in collectivist and overtly patriarchal cultures may increase the chances of self-blame occurring in victims from these groups. Myths about CSA (Collings, 1997) shift culpability for the crime from the offender to the victim, with the effect of protecting and preserving patriarchal structures due to the gender bias in victims with between 3:1 and 4:1 of victims being female perpetrated by males (Chen et al., 2004; Wang \& Heppner, 2011; Thornton \& Veenema, 2015; WHO, 2002). For example, Reavey et al. (2006) say, "suppression, purposeful forgetting, and internalising blame associated with sexual abuse increase susceptibility to suicide, self-harm, and depression in South Asian women (in the UK)” (p. 181). Pereda, Guilera, Forns, and Gomez-Benito (2009) also say "in (Asian) cultures influenced by Confucianism, in which a major characteristic is its patriarchal perspective, ascribing relatively high status to males and relatively low status to females, sexually abused girls may (then) blame themselves for their situation, which could lead to severe psychological effects beyond the immediate consequences of the sexual abuse" (p. S46). 
In the context of “women's (lack of) autonomy over their lives in a highly patriarchal society, Meng (2002), who explored the meaning of suicide in-depth by retrospectively analysing a series of ethnographic interviews with a woman in rural China before her death, frames the meaning of suicide for Chinese women as an act of revenge and one of the ways for women to rebel against their oppressive status in society; a real denouncement of the unequal relationship between genders. (Thus), the extreme stigmatisation experienced by survivors may increase the likelihood of suicide" (cited in Stewart, 2005, p. 9).

Heise (1993) also says, "in some societies, female suicide is regarded as a socially sanctioned behaviour that enables the politically powerless or entrapped to avenge those who have made their lives intolerable. Suicide is a 'culturally acceptable way out' of an abusive marriage, (and for some) the only viable alternative to eventual murder by the husband or his family ... (so they are more like) 'forced suicides' or 'disguised homicides"” (cited in Stewart, 2005, p. 9).

\subsection{The treatment needs of victims}

So far, the literature indicates that there are a multitude of barriers to help-seeking among ethnic minority communities. It also indicates that risks to well-being for a victim/survivor are already vast but could be amplified for victims from ethnic minority communities because of an unyielding and silencing need to protect the family name and patriarchal structures, in turn leading to a reliance on avoidance coping strategies and/or self-blame, which are both associated with poorer outcomes on mental well-being including risk for suicidality.

There is little literature on predictors of help-seeking among minority groups. Only one possible facilitator was identified - acculturation (Kanukollu \& Mahalingam, 2011). Haboush and Alyan (2013) say, for example, "the degree to which Arab Americans identify with either Arab or Western/European culture will impact the assessment and treatment of child sexual abuse" (p. 503). Foynes et al. (2014) similarly say, "treatment providers must strive to understand how adherence to cultural values affects likelihood of disclosure and multiple levels of the recovery process (e.g. beliefs about treatment, meaning attributed to trauma)" (p. 139). Finally, Singh (2009) says, "South Asian immigrant women who ascribed to patriarchal norms were less likely to view intimate partner violence as abuse, (which) delays help-seeking” (p. 364).

However, the predictive validity of acculturation can only be explored in hindsight once the victim has actually sought help. Thus, its facilitating role and how it could be nurtured is difficult to understand and unpack before help-seeking has occurred. Overall, there are many barriers that victims need to cross before they are willing to 
seek extra-familial professional help. Thus, at this point, the clinical environment must be ready for them in a way that will then competently meet their needs. Characteristics of effective treatment are described below, and again have uniquely been categorised in this article into four broad themes that can assist practitioners in identifying the key issues in need of consideration for the clinical setting: (i) cultural competency, (ii) cultural knowledge, (iii) self-help, and (iv) family and group therapy.

\subsubsection{Delivering services high on cultural competency}

The literature on best practice in regards to child maltreatment more broadly (rather than CSA more specifically) and ethnic minority communities identifies cultural competency as critical. Cultural competency is comprised of several elements, and operates at three levels - practitioner, organisational, and policy (Sawrikar \& Katz, 2008). Moreover, 'cultural competency' is a fluid process rather than a state that is attainable, so practitioners and organisations can grow and fall in it depending on the extent to which they implement its various elements (described below).

\subsubsection{Choice about an ethnically-matched service provider}

One critical element of cultural competency is choice for the client in whether they prefer an ethnically-matched or non-matched service provider (Sawrikar, 2017). Matched providers may be able to offer (tacit) cultural knowledge and awareness, and therefore appropriate sensitivity. However, the client's fear that someone from their ethnic community, and in the public, knows of their abuse and that they are seeking help outside of the family, may be so great that they prefer to have a professional from a different cultural background. Thus, it should not be assumed that clients will want a worker from their own cultural background (Allimant \& OstapiejPiatkowski, 2011; Fontes \& Faller, 2009; Gilligan \& Akhtar, 2005; Nesci, 2006).

In the service context, it is important for workers to repeatedly assure families of confidentiality (Sawrikar, 2017) to protect the client family's name (and sometimes even their physical safety). Reavey et al. (2006) also critically identify that there is a risk that clients with matched workers may be "persuaded to 'go home' and resolve the situation" (p. 174), demonstrating that the sensitivity they are assumed to offer does not always occur.

\subsubsection{Training interpreters on matters to do with sexual assault}


Another component of cultural competency is the provision of an interpreter if it is required (Sawrikar, 2017). Importantly, interpreters need to be trained on how to work sensitively and appropriately in matters to do with sexual assault (Fontes \& Faller, 2009). This can help avoid the risk of untrained interpreters making the session more about themselves, such as by crying for the client family, escalating matters, and/or being a trigger for their own possible history of sexual assault (Sawrikar, 2015).

\subsubsection{Having staff from ethnic minority communities, and choice between mainstream and ethno-} specific services

Cultural competency also asks for workers from minority communities to be employed in service organisations (Fontes, 2005), so that there is a diverse pool available for clients to choose from (Sawrikar, 2017). These workers would also need to be employed at management levels, where there is decision-making power (Sawrikar, 2017). In the words of one participant in a study conducted by Sawrikar (2017) on how to work effectively with ethnic minorities in Australian child protection systems, "If you look at management, it's all white. People with an accent, who weren't born here, get over-looked. Unless that changes, it's very difficult for the culture in the workplace to change”.

The study by Takeuchi et al. (1995) found that ethnicity-specific programs for Asian Americans were 6.6 times more likely to match client-therapist ethnicity than mainstream programs, and that Asian American clients in ethnicity-specific programs were more likely to return after the first session and stay for more treatment sessions compared to Asian Americans in mainstream programs" (cited in Futa et al., 2001, p. 198). Thus, the findings also highlight the importance of having choice between mainstream and culturally specific organisations.

\subsubsection{Providing cultural competency training}

Another component of cultural competency is the routine provision of training by management to all staff in service organisations (Sawrikar, 2017). This is because ethnic diversity in the populace means that all workers will need knowledge about different others (Nesci, 2006; Sawrikar, 2013; Tishelman \& Geffner, 2010). To address staff turnover and the need for knowledge about new and emerging groups, this training should be provided regularly (Sawrikar, 2017).

\subsubsection{Using a 'multicultural framework'}


Meeting language needs (with an interpreter trained in sexual assault matters) and the needs of clients fearful of a breach of confidentiality (with an ethnically non-matched professional trained in cultural competency) are relatively easy, compared to the much larger issue of having a service organisation with a 'multicultural framework'. This component of cultural competency asks for organisations/institutions to have a philosophy that values diversity and unwavering commitment to respect diversity.

Potential clients from minority groups may feel "distrustful of white organisations" (Race, 1999, cited in Gilligan \& Akhtar, 2005, p. 270), and "fear discrimination (as a result of) culturally racist clinical and social work practices" (Reavey et al., 2006, p. 173). For example, Haboush and Alyan (2013) report that "following the September 11 attacks, many Arab Americans have reported increased discrimination, associated with a reluctance to interact with formal systems (and ability to) establish trust with mental health professionals" (p. 511). Moreover, they go on to say that, "in American society, nearly every report of sexual abuse results in some form of contact with legal and medical systems, including child protective services, emergency room medical forensic examinations, and prosecution. Negative responses from the formal system (judgment, blaming the victim) significantly exacerbates PTSD symptomology through a secondary traumatisation process, giving rise to the hypothesis that such a response would be particularly deleterious in the case of Arab-American children who may also be experiencing such a reaction from family or community members" (Haboush \& Alyan, 2013, p. 512).

Racist discrimination may be particularly feared by new arrivals (Haboush \& Alyan, 2013) and those who are visibly different from the mainstream, e.g. through skin colour, religious attire, etc. (Sawrikar, 2017). Indeed, half-Anglo, mixed race children are at risk of not having their cultural needs addressed in the Australian child protection system (Sawrikar, 2017), demonstrating how "white people (are) often considered "culture free"” (Fontes, 1997, cited in Kenny \& McEachern, 2000).

Thus, deep self-reflection by all service providers (especially mainstream) on how their own culture is entwined with the experience of CSA (especially the collectivist/familial and patriarchal elements which are comparatively less overt), as well as non-racist attitudes, practices, and policies by both workers and their agencies, are called for to ensure that different/non-mainstream others are not judged or vilified. As Allimant and Ostapiej-Piatkowski (2011) put it, implicitly or explicitly judging a non-Western/collectivist culture "as 'inferior' or 'cruel' contributes to minimising a woman's perception of self-efficacy and life achievements, in addition to being offensive toward her community and culture. The Western way of life and its values are just 
one way of framing the world and behaviour" (p. 7). Judging and vilifying patriatrchal and collectivist culture "pathologises culture as if it were deficient rather than seeing groups as unique with something unique to offer in response to child sexual abuse" (Gilligan \& Akhtar, 2005, p. 277). Thiara, Roy, and Ng (2015) also report that in some service organisations in the UK, there is "a lack of understanding about BME (black and ethnic minority) women's experiences (that) stemmed from an excessive focus on 'culture', seen to view sexual violence as 'normal' in those communities" (p. 5).

Masehela and Pillay (2014) also say of the African context: "describing sex and sexuality in terms of modernist and African traditions exposes the ambiguities that create confusion in post-colonial African society. Urbanites and Western globalists regard themselves as superior to the uninformed or primitive societies of rural Africa. In stark contrast, African (rural) communities want to retain their Indigenous ways of doing things, and this has nothing to do with being inferior or superior. According to them, such practices help them to remain stable and maintain the political authority of the amakhosi (chiefs). African communities cling to their customs regardless of how well these serve them, as long as their customs make them feel safe" (p. 24).

In addition to the risk of judging collectivist and patriarchal cultures, the lack of a multicultural framework could also lead to a risk of judging poverty in developing nations. For example, Capri (2013) found that "child sexual abuse narratives were entangled with themes of hunger, deprivation, abandonment, violence, and pervasive poverty" (p. 35) in South Africa. She also points out that "therapists work with limited resources in situations of poverty, (and as a result), should guard not only against compassion fatigue, but also against system fatigue - the result of fighting to do good work in an unworkable yet inescapable system” (p. 48).

"In the Jamaican context, some predators may solicit consent from the minor's caretaker in exchange for goods or favours. (Thus), the child is not a child in his or her own right, but mere property, capable of generating income" (Gibson et al., 2007, p. 112). "Parents (may also) encourage children to prostitute themselves to tourists and others for monetary income (and) it appears the common societal response is largely 'to turn a blind eye' in order to keep certain deviant tourists happy. Such inaction has been historic” (Gibson et al., 2007, p. 114). Pasura et al. (2012) says that in the Caribbean, there is "almost an acceptance of CSA as 'normal' and inevitable for some children" (p. 205).

Sossou and Yogtiba (2009) also say of the West Africa context, "having a child is a defining characteristic of most traditional African families, as children are symbols of status, respect and completeness of the nuclear family. Some view life without a child as meaningless and would do anything to have a child. The African child 
is born in(to) a very welcoming and accepting culture, where everybody is ready for his/her arrival and his/her basic needs are even met before he/she arrives. However, the situation of children in West Africa today is undermined by poverty, malnutrition, child labour, rural-urban migration, ignorance, and lack of education, parental lack of financial support, and maintenance of children. (Thus), children in West Africa are more likely to be raped, trafficked, beaten, or abused and are less likely to go to school, receive proper health care or be properly nourished compared with fifteen years ago, despite binding legislations meant to improve children's situation" (p. 1218-9).

Madu and Peltzer (2000) say, "many children (living in poverty) would be easily lured into sexual abuse with gifts" (p. 264). For example, "sugar daddies" and "sugar mommies" in Cameroon may be a source of food, shelter, or school fees, in return for sexual services" (Lalor, 2004, p. 449). In Jamaica, "it is not uncommon for children to choose between pursuing an education and alleviating themselves and families from poverty by conducting sexual favours" (Samms \& Cholewa, 2014, p. 118). Interestingly, Lewis (2012) says “the Pacific Regional Rights Resource Team estimate many thousands of Papua New Guineans are connected to the commercial sexual exploitation of children (which) provide children with freedom and money to support themselves. (However) the commercial sexual exploitation of children seems better studied than intrafamilial CSA (perhaps because it is) less controversial, particularly in a country where Christianity is so important to its legal and social fabric" (p. 274).

Importantly, Mildred and Plummer (2009) say, "it is essential we avoid assuming, explicitly or implicitly, that more affluent or "developed" countries inevitably represent more fully developed or sophisticated approaches. This may be challenging, at times, for experts from affluent countries who are consulting about and/or working with sexual abuse issues in less affluent areas of the world because our greater resources, our longer histories of responding systematically to this issue, our larger fund of research-based knowledge, and our more established programs and policies may lead us and some of our Southern hosts to see our relationship as a one-way or "top down" process of teaching or consulting. This kind of relationship limits mutual learning and ignores the dangers inherent in offering practices developed for application in one social, political, and economic context as models for implementation in another" (p. 602).

Tervalon and Murray-García (1998) refer to “self-awareness and habits of self-reflection as 'cultural humility'. (It is critical to good practice because) even when professionals are unaware of (racial) biases and assumptions, clients often perceive them" (cited in Fontes \& Plummer, 2010, p. 509). As Gilligan and Akhtar (2006) put it, 
"practitioners need to remain alert to the fact that they are at risk of misinterpreting the behaviour of people whose culture they are not familiar with, particularly if they approach such situations with an insufficient awareness of their own potential for ignorance" (p. 1372).

Thus, a counsellor is required to have "cross-cultural understanding and ability to sit with the other's worldview" (Allimant \& Ostapiej-Piatkowski, 2011, p. 4). If they do not, it can add extra harm to the victim in the form of failing to validate their perception and comprehension of the violence incurred. It can also risk the victim retreating from help that would have already been extremely difficult to seek in the first place. As one example, Allimant and Ostapiej-Piatkowski (2011) report that "workers in mainstream agencies (in Australia) may ask inappropriate questions about family structure, spiritual beliefs, or parenting, or they may say the family has "been here long enough to speak English"” (p. 10). Stewart (2005) also points out "a tendency among mental health professionals to pathologise culture (based on) constructions of cultural stereotypes that form the bedrock of a potentially racist mental health discourse" (p. 10).

Overall, the elements of good service delivery point simply to a 'humane' approach. Services should be approachable and culturally sensitive (Gilligan \& Akhtar, 2005; Kaur, 2009), clients should be listened to in a confidential and non-judgemental setting, receive appropriate referrals to services in the local community and information in an accessible formats (Allimant \& Ostapiej-Piatkowski, 2011; Singh, 2009), and be spoken to with a warm, respectful, and supportive tone (Fontes \& Plummer, 2010).

The literature reports that some white practitioners are "fearful of offending" (Allimant \& Ostapiej-Piatkowski, 2011, p. 6). This is, in fact, seen as a positive. It is seen to indicate that there is awareness that racial relations are politicised along the lines of differential social power and that there is a need for cultural sensitivity. However, these workers may need additional support on how to implement that sensitivity in a way that effectively meets the needs of the clients. Sometimes, this can mean "tackling issues of culture head on and not seeing it as a background to the main task of discussing the sexual abuse" (Reavey et al., 2006, p. 178). At other times, "too much focus on difference perpetuates an 'us and them' way of thinking” (Stewart, 2005, p. 13). Thus, fear of offending simply needs to be harnessed into a sense of efficacy, where workers are able to not "overemphasise differences and neglect similarities between groups or deny the diversity within them" (Fontes, 1997, cited in Kenny \& McEachern, 2000, p. 919); an effective balance between 'universalism' and 'cultural appropriateness' is found. 
In short, failure to recognise differences in social power between the mainstream and minority groups at the organisational/institutional level, risks adding further trauma to the victim who has already suffered a severe abuse of power. Implementing cultural competency is thus not only valuable, but "an absolute necessity" (National Centre for Cultural Competency, 2006, cited in Allimant \& Ostapiej-Piatkowski, 2011, p. 7). All parties in the clinical setting could have a lot of work to do; white practitioners and mainstream organisations may need to internalise the ethical onus to be aware of 'White privilege', while clients of all backgrounds may need to be encouraged to deeply reflect on gender inequality as a root cause of CSA so that it is not at risk of being downplayed or deflected. As Allimant and Ostapiej-Piatkowski (2011) put it, "behind its apparent simplicity, effective service delivery is deceptively complex" (p. 6). Overall, complacent cultures of silence do not excuse the violation of human rights, but they do need to be addressed in ways that do not disempower minority communities. That is, services should not collude with community pressures to silence or blame victims, but instead engage with communities respectfully and constructively.

In the context of IPV among South Asian women victims in Canada, Ahmad et al. (2009) argue that women who accept horizontal-collectivism, as opposed to vertical-collectivism, are more likely to self-sacrifice their personal happiness, even their lives, to achieve family unity and therefore the collective good especially for their children. Horizontal-collectivism maintains the positive aspects of familism (i.e. community belonging) but rejects the association of collectivism with patriarchy, striving for more gender equality in relationships. Vertical-collectivism capitalises on the "exploitation" and "misuse" of familism and collectivism (p. 620). By analogy, CSA currently operates within a vertical-collectivist framework. One strategy for engaging ethnic minorities in empowering, reflective, and productive ways is to encourage them to strive for horizontalcollectivism, by "emphasising the welfare of daughters/sisters/nieces over and above family honour" (Ahmed, Reavey, \& Majumdar, 2009, p. 19).

\subsubsection{Data collection}

In addition to a respectful and inclusive philosophy, cultural competency asks of service organisations to mandatorily collect data on variables related to ethnicity (Kaur, 2012; Sawrikar, 2017; Thiara et al., 2015), such as countries of birth of family members, languages spoken at home, citizenship status, refugee pathways of entry, etc. As an example, Pittaway and Rees (2005-06) say that "it is estimated that the majority of refugee women and children have suffered repeated rape and sexual assault. However, there is no data stating how many refugee women and children in Australia have experienced sexual assault, how many of them are accessing 
support services, nor how frequently" (cited in Allimant \& Ostapiej-Piatkowski, 2011, p. 2). Thus, service organisations would improve their responsiveness and capacity to advocate for the needs of victims from minority communities with better data and data collection protocols (while also being mindful to do so in a culturally appropriate way).

\subsubsection{Cultural knowledge regarding the use of 'medicalised discourse'}

Unlike cultural competency, which is a necessary component of service delivery in multicultural countries like Australia, cultural knowledge is not necessary but is certainly helpful. One example of this is awareness of the pros and cons of using medicalised discourse, which emerged as a theme in the literature. In some circumstances, it may be helpful for victims from ethnic minority communities, and at other times not, and it is critical to know when that might be the case. Such cultural knowledge could be delivered in cultural competency training programs for service providers.

In some cultures, such as Asian Americans (Kenny \& McEachern, 2000), “emotional/mental distress may be somatised because 'mental illness' is highly stigmatised" (Stewart, 2005, p. 8). Haboush and Alyan (2013) also say, "Arab culture tends to find somatic expressions of emotional distress more acceptable; thus, medication for psychiatric symptoms may be preferred over talk therapies. Doctors are viewed as authoritative figures with a great degree of respect and, as such, seeking medical treatment for emotional problems is often less shameinducing. Thus, a family's receptiveness to medical intervention for the child should be considered, especially since PTSD is associated with numerous medical symptoms” (p. 513). Allimant and Ostapiej-Piatkowski (2011) similarly say, "culturally and linguistically diverse women may not name the violence as such (and so) first seek medical advice or spiritual counsel to help "fix" themselves" (p. 7).

Reavey et al. (2006) point out that "the deployment of illness categories, embedded within a medical and psychotherapeutic framework, deflect attention away from having to touch on the wider 'problematics' of the (South Asian) woman's surrounding cultural influences, such as the complexities of enmeshment in a cultural system that might not readily permit talk of sexual abuse or an abuse of power by a male partner, (and thus her) lack of engagement with a survivor identity. (In this sense), the adoption of psychiatric terminology is considered by some professionals to be a positive and pragmatic solution to the problem of speaking about the abuse. The application of a label such as 'depression', 'anxiety', or 'post-traumatic stress disorder' legitimates women's psychological difficulties with the sexual abuse they have experienced (and that) a legitimate authority can be called upon to reinforce such an intervention" (p. 182). 
The most significant problem with this approach, however, is that "there is a risk that problems with abusive experiences become internalised and individualised. Social problems and dynamics then turn into mental disorders that require individual resolve" (Reavey et al., 2006, p. 183). Gilbert, Gilbert, and Sanghera (2004) report that "one of the major barriers to accessing services among South Asian women (in the UK) was the fear that their very real problems would be redefined as 'crazy' or (they would be) labelled 'mad'. This 'fear' was grounded, as a label may very well allow women to continue to be abused because the problem has been located in the woman, rather than in the context of her everyday circumstances. (Thus), therapy that reduces 'symptoms' should be completely mindful of the contexts that sustain those 'symptoms' in the first place" (cited in Reavey et al., 2006, p. 184). As Wang and Heppner (2011) put it, "a unilateral focus on the treatment of borderline personality disorder, rather than the impact of the child sexual abuse, may significantly impede treatment progress" (p. 406).

Interestingly, Ajzenstadt and Cavaglion (2005) report that the "efforts of feminist activists (in Israel) in bringing violence against women and child abuse prevention to the public agenda have been "largely unsuccessful"; in comparison, mental health and social work professionals have had more influence" (p. 257). This suggests that in overtly patriarchal societies, CSA prevention may be more likely to be advanced by 'medical' professionals. Importantly, medicalising treatment also risks "exclusion of lay persons through utilisation of specialised, professional language ... (and) relations of power connected to the abusive behavior are ignored and the marginalisation of children - especially girls - is reinforced” (Ajzenstadt \& Cavaglion, 2005, p. 266-7). That is, medicalised discourse facilitates organisations/institutions being able to deny unequal power distributions across gender. Thus, CSA in the clinical setting needs to be understood within its social and political context, not just a medical one.

\subsubsection{Suggesting self-help treatment}

Medicalising the discourse around CSA is also problematic in that it gives power to professionals, falsely giving the message that "children can only recover with expert help ... and that like a physical disease, sexual abuse can be overcome" (Ajzenstadt \& Cavaglion, 2005, p. 265-6). It is important that formal service organisations acknowledge they are but one source of help and not give false hope. Lev-Wiesel (2000) says, for example, "we as practitioners must remain cautious of omnipotent thoughts, and take care not to entrap ourselves in the belief that we are able to help all survivors to release their negative feelings towards themselves, and that all such individuals can, in fact, be healed" (p. 11). Thus, self-help strategies should additionally be encouraged. 
One self-help strategy may be e-based treatment. Chien (2013) says "due to the strong taboo of sexuality and the unspeakable secret of child sexual abuse in Chinese society, self-healing and bibliotherapy may serve a particularly crucial function for survivors. These methods may allow Chinese child sexual abuse survivors to help themselves at their convenience in an unobtrusive way" (p. 267). Alao and Molojwane (2008) similarly say, "one option to assist victims of child sexual abuse (in Botswana) is to provide on-line counselling as an immediate intervention of support" (p. 17). Thus, e-based treatment appears useful for its anonymity and availability.

Another self-help strategy identified in the literature was narrative therapy. Smith et al. (2010) note that "narrative interventions utilised in the psychotherapeutic treatment of child sexual abuse survivors might assist them to cast themselves as empowered, competent, and connected human beings. (That is), narrative therapy can help the female child sexual abuse survivor shed her former identity as a child sexual abuse survivor engulfed in self-blame and reinvent herself as the empowered, loved, and nurtured heroine in her own story” (p. 268).

Finally, music therapy may play a role in the 'self-help space'. Schrader and Wendland (2012) note that "music therapy offers an important vehicle for expression and healing for child survivors of sex trafficking (in Cambodia). Oftentimes, children in therapeutic settings lack the language and metacognition required to benefit from typical verbally based therapies. Because music is processed holistically at the brain stem, midbrain and cortical levels, music activities can be designed to elicit behavioural or physiological changes that do not require the use of higher-level cognition or language skills" (p. 392). As Smyth (2002) notes, "the expressive nature of music can facilitate expression of difficult emotions, and music can help break the silence of isolation" (p. 78, cited in Schrader \& Wendland, 2012, p. 392). Music therapy has also been shown to be effective among refugees and asylum seekers in Australia (Lenette \& Sunderland, 2016; Lenette, Weston, Wise, Sunderland, \& Bristed, 2015).

\subsubsection{Suggesting family and group therapy}

Given the many barriers to professional help-seeking among ethnic minority communities, it may be difficult to raise participation in family and group therapy. Indeed, little research on family and group therapy for collectivist-based cultures was identified in the review. Nevertheless, awareness of such services in the local community is still required, as they can serve critical functions. 
"Child sexual abuse does not happen within a vacuum. Witnessing the harm, or even knowledge of it, can itself be traumatising. As a result, sexual abuse can extend beyond the primary victim to secondary victims, such as family, friends, work colleagues, and even whole communities" (Working Definitions, Royal Commission into Institutional Responses to Child Sexual Abuse).

As Sil and Soo (2008) point out, "the impact of sexual abuse is not solely a child problem; it is a family problem. In intra-familial sexual abuse cases, the family must participate to increase the child's safety and parental support, and to reduce the risk of re-abuse. Treatment components (therefore need to) include treatment of the abused child, sibling treatment, non-offending parent treatment, offender treatment, and family treatment" (p. 81).

Corcoran and Pillai (2008) similarly say, "although the sexually abused children are unquestionably the victims, clinicians should not rule out the fact that the parents and caregivers may also experience emotional distress as a result of their child being sexually assaulted. (Thus), clinicians need to implement treatment plans that include the parents/caregivers and/or the family as a whole, including a psychoeducation component so they can identify and respond to signs of sexual abuse" (cited in Samms \& Cholewa, 2014, p. 123-4).

In addition to family therapy, abused children may also benefit from participation in group therapy with other abused children (Stevenson, 1999, cited in Fanslow, Robinson, Crengle, \& Perese, 2007). As Chitereka (2010) puts it, "group therapy allows children (in Zimbabwe) to confront and work through experiences with a group of peers struggling with similar issues. This is powerful in the healing process, because the sexually abused child feels isolated from his or her peers. Sharing the experience in a group format can lessen the loneliness" (p. 37).

\section{Discussion}

\subsection{Summary of key findings}

The results of this exhaustive literature review indicate that there are many elements comprising the treatment needs of victims/survivors of CSA from ethnic minority communities. Summarily, they include service delivery high in cultural competency, cultural knowledge about medicalised discourse, and encouragement of self-help therapies. Of all these, however, the use of a 'multicultural framework' - an element of cultural competency - is seen as the most important. It refers to unwavering commitment to respect cultural differences, most especially collectivist and overtly patriarchal groups. Given Australia's paucity in research, the identification of these key themes from the international literature play a critical role in the development of national frameworks; a sorely 
needed endeavour in light of its high multicultural milieu but with no current research to help inform or standardise practice.

The results also indicate that there are many barriers to help-seeking in ethnic minority communities, most especially due to the normative reliance on intra-familial support and shame for seeking extra-familial support. Arguably, 'consultation studies' could be conducted to help identify culturally appropriate strategies for addressing them. Positively, such studies would be an example of community action and participatory research (Itzhaky \& York, 2001; Reid, Reddock, \& Nickenig, 2014; Sullivan, Bhuyan, Senturia, Shiu-Thornton, \& Ciske, 2005). Ahmad et al. (2009) also say - about IPV in South Asian communities in Canada, but with transferability to the context of CSA - "provider recognition of the multiple reasons of South Asian women's delayed helpseeking is essential for compassionate care, vigilance, and persistence in asking about stress and abuse in intimate relationships" (p. 620). Importantly, not all barriers to help-seeking are cultural, and interact with other non-cultural and systemic barriers such as fear of authorities and lack of culturally sensitive support services.

Overall, barriers lead to delays in seeking professional help which can amplify the already extensive array of risks to well-being including risk of suicidality. Thus, the provision of effective treatment is critical for victims from minority groups.

\subsection{Conclusion}

Mennen (1995) says that "many researchers and professionals in the field of child maltreatment would likely argue that the unique circumstances of the sexually abusive experience (e.g. relationship with perpetrator, nature of the abuse, duration, etc.) are more strongly related to the distress a victim suffers than racial or ethnic factors" (cited in Back et al., 2003, p. 1262). However, the emerging body of research suggests that symptoms of mental illness may be worse for some minority victims if they are 'suffocating in silence', mandated by cultural expectations to do so. This makes clinical intervention particularly critical for them, and highlights that crosscultural variations in the needs and experiences of victims/survivors do occur.

However, clinical intervention is not the only form of support available. Moreover, the symptoms of mental illness as a result of the victimisation may be so severe that therapy can do little to alleviate them. Nevertheless, formal systems must do all they can to design a service that is high on cultural competency, so that when victims finally muster the courage to see themselves as worthy of professional help and tolerate stigma or fear for doing so, they are equipped to best their needs. This is perhaps a tall order as there are many elements to consider. 
Thus, treatment may require a combination of simplicity (so as not to overwhelm workers) with the use of a 'humane' approach, and complexity (so as not to reduce the needs of clients from minority groups) with up-todate cultural awareness and knowledge. 


\section{References}

Ahmad, F., Driver, N., McNally, M. J., \& Stewart, D. E. (2009). "Why doesn’t she seek help for partner abuse?" An exploratory study with South Asian immigrant women. Social Science \& Medicine, 69(4), 613-622.

Ahmed, B., Reavey, P., \& Majumdar, A. (2009). Constructions of 'culture' in accounts of South Asian women survivors of sexual violence. Feminism \& Psychology, 19(1), 7-28.

Ajzenstadt, M., \& Cavaglion, G. (2005). Stories about child sexual abuse: Textual analysis of instruction manuals in Israel. Qualitative Sociology, 28(3), 255-274.

Alao, A. A., \& Molojwane, M. B. (2008). Childhood sexual abuse: The Botswana perspectives. Child Sexual Abuse: Issues and Challenges, 9-18.

Allimant, A., \& Ostapiej-Piatkowski, B., (2011). Studies, (2011). Supporting women from CALD backgrounds who are victims/survivors of sexual violence: challenges and opportunities for practitioners. Australian Centre for the Study of Sexual Assault (ACSSA) Wrap, No. 9, 1-16, Melbourne: Australian Institute of Family Studies. Australian Bureau of Statistics (2012-13). Cultural diversity in Australia - Reflecting a Nation: Stories from the 2011 Census (Cat. No. 2071.0). Canberra: Author.

Back, S. E., Jackson, J. L., Fitzgerald, M., Shaffer, A., Salstrom, S., \& Osman, M. M. (2003). Child sexual and physical abuse among college students in Singapore and the United States. Child Abuse and Neglect, 27(11), $1259-1275$.

Baker, C. K., Gleason, K., Naai, R., Mitchell, J., \& Trecker, C. (2013). Increasing knowledge of sexual abuse: A study with elementary school children in Hawai’i. Research on Social Work Practice, 23(2), 167-178.

Barker-Collo, S., Read, J., \& Cowie, S. (2012). Coping strategies in female survivors of childhood sexual Abuse from two Canadian and two New Zealand cultural groups. Journal of Trauma and Dissociation, 13(4), 435-447.

Barnes, J.E., Noll, J. G., Putnam, F. W., \& Trickett, P. K. (2009). Sexual and physical revictimization among victims of severe childhood sexual abuse. Child Abuse and Neglect, 33, 412-420.

Berry, J. W. (1980). Acculturation as varieties of adaptation. In A. M. Padilla (Ed.), Acculturation: Theory, models, and some new findings. Boulder, CO: Westview. 
Bond, M. H. (2002). Reclaiming the individual from Hofstede's ecological analysis - A 20-year odyssey:

Comment on Oyserman et al. (2002). Psychological Bulletin, 128, 73-77.

Bromfield, L. \& Arney, F. (2008) Developing a road map for research: Identifying priorities for a national child protection research agenda: Issues paper. Australian Institute of Family Studies, No 28.

Burke, S. \& Paxman, M. (2008). Children and young people from Non-English speaking backgrounds in Out of Home Care in NSW. Sydney: NSW Department of Community Services.

Capri, C. (2013). Madness and defence: Interventions with sexually abused children in a low-income South African community. European Journal of Psychotherapy and Counselling, 15(1), 32-52.

Cashmore, J., Higgins, D. J., Bromfield, L., \& Scott, D. A. (2006). Recent Australian child protection and out of home care research: What's been done and what needs to be done? Children Australia, 31(2), 4-11.

Chen, J. Q., \& Chen, D. G. (2005). Awareness of child sexual abuse prevention education among parents of Grade 3 elementary school pupils in Fuxin City, China. Health Education Research, 20(5), 540-547.

Chen, J., Dunne, M. P., \& Han, P. (2004). Child sexual abuse in China: A study of adolescents in four provinces. Child Abuse and Neglect, 28(11), 1171-1186.

Chien, M-h. (2013). Identifying key components of an Internet Information System for Chinese survivors of childhood sexual abuse. Journal of Ethnic \& Cultural Diversity in Social Work, 22(3-4), 256-270.

Chien, M-h. (2008). The current relationships of Taiwanese women with a history of childhood sexual abuse to their non-offending mothers. Journal of Social Service Research, 34(4), 29-39.

Chitereka, C. (2010). Child sexual abuse in Zimbabwe: An agenda for social work. Asia Pacific Journal of Social Work and Development, 20(1), 29-40.

Collings, S, J. (1997). Development, reliability, and validity of the child sexual abuse myth scale. Journal of Interpersonal Violence, 12(5), 665-674.

Corcoran, J., \& Pillai, V. (2008). A meta-analysis of parent involved treatment for child sexual abuse. Research on Social Work Practice, 18, 453-463. 
Elbedour, S., Abu-Bader, S., Onwuegbuzie, A. J., Abu-Rabia, A., \& El-Aassam, S. (2006). The scope of sexual, physical, and psychological abuse in a Bedouin-Arab community of female adolescents: The interplay of racism, urbanization, polygamy, family honor, and the social marginalization of women. Child Abuse and Neglect, 30(3), 215-229.

Fanslow, J. L., Robinson, E. M., Crengle, S., \& Perese, L. (2007). Prevalence of child sexual abuse reported by a cross-sectional sample of New Zealand women. Child Abuse and Neglect, 31(9), 935-945.

Feiring, C., Coates, D. G., \& Taska, L. S. (2001). Ethnic status, stigmatization, support, and symptom development following sexual abuse. Journal of Interpersonal Violence, 16, 1307-1329.

Fontes, L. A., \& Plummer, C. (2010). Cultural issues in disclosures of child sexual abuse. Journal of Child Sexual Abuse, 19(5), 491-518.

Fontes, L. A., \& Faller, K. M. L. C. (2009). Conducting culturally competent sexual abuse interviews with children from diverse racial, cultural, and socioeconomic backgrounds. Interviewing children about sexual abuse: Controversies and best practice.

Fontes, L. A. (2005). Child abuse and culture: Working with diverse families. New York: Guilford Press.

Fontes, L. (1997). Evaluating the cultural sensitivity of child abuse research: Sampling issues. American Professional Society on the Abuse of Children Advisor, 10, 8-10.

Fontes, L. (1993). Considering culture and oppression. Journal of Feminist Family Therapy, 5(1), $25-54$.

Foynes, M. M., Platt, M., Hall, G. C. N., \& Freyd, J. J. (2014). The impact of Asian values and victimperpetrator closeness on the disclosure of emotional, physical, and sexual abuse. Psychological Trauma: Theory, Research, Practice, and Policy, 6(2), 134-141.

Freeman, D. H., Jr., \& Temple, J. R. (2010). Social factors associated with history of sexual assault among ethnically diverse adolescents. Journal of Family Violence, 25(3), 349-356.

Futa, K. T., Hsu, E., \& Hansen, D. J. (2001). Child sexual abuse in Asian American families: An examination of cultural factors that influence prevalence, identification, and treatment. Clinical Psychology: Science and Practice, 8(2), 189-209. 
Gibson, C., Emeka, T. Q., \& Walters, N. (2007). Sexual abuse of minors in Jamaica: Understanding predator, prey, and citizenry. Journal of Ethnicity in Criminal Justice, 5(2-3), 109-122.

Gilbert, P., Gilbert, J., \& Sanghera, J. (2004). A focus group exploration of the impact of izzat, shame, subordination and entrapment on mental health and service use in South Asian women living in Derby. Mental Health, Religion and Culture, 7, 109-130.

Gilligan, P., \& Akhtar, S. (2006). Cultural barriers to the disclosure of child sexual abuse in Asian communities: Listening to what women say. British Journal of Social Work, 36(8), 1361-1377.

Gilligan, P., \& Akhtar, S. (2005). Child sexual abuse among Asian communities: Developing materials to raise awareness in Bradford. Practice (UK), 17(4), 267-284.

Haboush, K. L., \& Alyan, H. (2013). “Who can you tell?” Features of Arab culture that influence conceptualization and treatment of childhood sexual abuse. Journal of Child Sexual Abuse, 22(5), 499-518.

Haj-Yahia, M. \& Tamish, S. (2001). The rates of child sexual abuse and its psychological consequences as revealed by a study among Palestinian university students. Child Abuse and Neglect, 25, 1303-1327.

Heise, L.L. (1993). Violence against women: the missing agenda. In M. Koblinski, J. Timyan \& J. Gay (Eds.), Women's Health: A Global Perspective, 171-195, Boulder: Westview.

Hofstede (2001): http://www.clearlycultural.com/geert-hofstede-cultural-dimensions/individualism/

Hofstede, G. H. (1980). Culture's consequences: international differences in work-related values. Beverly Hills, Calif: Sage Publications.

Itzhaky, H., \& York, A. S. (2001). Child sexual abuse and incest: Community-based intervention. Child Abuse and Neglect, 25(7), 959-972.

Jewkes, R. K., Dunkle, K., Nduna, M., Jama, P. N., \& Puren, A. (2010). Associations between childhood adversity and depression, substance abuse and HIV and HSV2 incident infections in rural South African youth. Child Abuse and Neglect, 34(11), 833-841.

Kanukollu, S. N., \& Mahalingam, R. (2011). The idealized cultural identities model on help-seeking and child sexual abuse: A conceptual model for contextualizing perceptions and experiences of South Asian Americans. Journal of Child Sexual Abuse, 20(2), 218-243. 
Karthiga, R. K. J., \& Ravikumar, R. (2014). Child sexual abuse in Madurai, India: A literary review and empirical study. Journal of Child Sexual Abuse, 23(6), 727-744.

Kaur, J. (2012). Australian research review on the needs of culturally and linguistically diverse (CALD) and refugee children and families Cultural Diversity and Child Protection.

Kaur, J. (2009). Developing 'culturally sensitive' practice when working with CALD communities in child protection - an Australian exploratory study. Developing Practice: The Child, Youth and Family Work Journal (23), 22-34.

Kenny, M. C., \& McEachern, A. G. (2000). Racial, ethnic, and cultural factors of childhood sexual abuse: A selected review of the literature. Clinical Psychology Review, 20(7), 905-922.

Korbin, J. E. (2002). Culture and child maltreatment: cultural competence and beyond. Child Abuse \& Neglect, 26, 637-644.

Krug, E. G., Dahlberg, L. L., Mercy, J. A., Zwi, A. B., Lozano, R. (2002). World Report on Violence and Health. Geneva: World Health Organisation.

Lalor, K. (2004). Child sexual abuse in sub-Saharan Africa: A literature review. Child Abuse and Neglect, 28(4), 439-460.

Laungani, P. (2003). Sexual abuse in an Asian family. Counselling Psychology Quarterly, 16(4), 385-401.

Lenette, C., \& Sunderland, N. (2016). "Will there be music for us?” Mapping the health and well-being potential of participatory music practice with asylum seekers and refugees across contexts of conflict and refuge. Arts \& Health, 8(1), 32-49.

Lenette, C., Weston, D., Wise, P., Sunderland, N., \& Bristed, H. (2015). Where words fail, music speaks: the impact of participatory music on the mental health and wellbeing of asylum-seekers. Arts \& Health: An International Journal for Research, Policy and Practice, advanced access. doi: 10.1080/17533015.2015.1037317.

Lev-Wiesel, R., \& Amir, M. (2005). Holocaust child survivors and child sexual abuse. Journal of Child Sexual Abuse, 14(2), 69-83. 
Lev-Wiesel, R. (2000). Quality of life in adult survivors of childhood sexual abuse who have undergone therapy. Journal of Child Sexual Abuse, 9(1), 1-13.

Lewis, I. R. (2012). At Risk: The relationship between experiences of child sexual abuse and women's HIV status in Papua New Guinea. Journal of Child Sexual Abuse, 21(3), 273-294.

Li, N., Ahmed, S., \& Zabin, L. S. (2012). Association between childhood sexual abuse and adverse psychological outcomes among youth in Taipei. Journal of Adolescent Health, 50(3, Suppl), S45-S51.

Libby, A. M., Orton, H. D., Novins, D. K., Beals, J., \& Manson, S. M. (2005). Childhood physical and sexual abuse and subsequent depressive and anxiety disorders for two American Indian tribes. Psychological Medicine, $35,329-340$.

Luo, T-Y. (2000). “Marrying my rapist?!”: The cultural trauma among Chinese rape survivors. Gender \& Society, 14(4), 581-597.

Luo, T. Y. (1987). Ethnic variations in sexual victimization: A preliminary analysis of Caucasians, Asians, and mixed-Asians in Hawaii. Unpublished master's thesis, Department of Sociology, University of Hawaii-Manoa.

Ma, E. Y., \& Li, F. W. (2014). Developmental trauma and its correlates: A study of Chinese children with repeated familial physical and sexual abuse in Hong Kong. Journal of Traumatic Stress, 27(4), 454-460.

Madu, S. N., \& Peltzer, K. (2000). Risk factors and child sexual abuse among secondary school students in the Northern Province (South Africa). Child Abuse and Neglect, 24(2), 259-268.

Mansbach-Kleinfeld, I., Ifrah, A., Apter, A., \& Farbstein, I. (2015). Child sexual abuse as reported by Israeli adolescents: Social and health related correlates. Child Abuse and Neglect, 40, 68-80.

Marie, D., Fergusson, D. M., \& Boden, J. M. (2009). Ethnic identity and exposure to maltreatment in childhood: evidence from a New Zealand birth cohort. Social Policy Journal of New Zealand, 36, 154-171.

Masehela, B., \& Pillay, V. (2014). Shrouds of silence: A case study of sexual abuse in schools in the Limpopo Province in South Africa. Perspectives in Education, 32(3), 22-35.

Mathews, S., Abrahams, N., \& Jewkes, R. (2013). Exploring mental health adjustment of children post sexual assault in South Africa. Journal of Child Sexual Abuse, 22(6), 639-657. 
Meade, C. S., Watt, M. H., Sikkema, K. J., Deng, L. X., Ranby, K. W., Skinner, D... \& Kalichmann, S. C. (2012). Methamphetamine use is associated with childhood sexual abuse and HIV sexual risk behaviors among patrons of alcohol-serving venues in Cape Town, South Africa. Drug and Alcohol Dependence, 126(1-2), 232239.

Meng, L. (2002). Rebellion and revenge: the meaning of suicide of women in rural China. International Journal of Social Welfare, 11, 300-309.

Mennen, F. E. (1995). The relationship of race/ethnicity to symptoms in childhood sexual abuse. Child Abuse and Neglect, 19, 115-124

Mildred, J., \& Plummer, C. A. (2009). Responding to child sexual abuse in the United States and Kenya: Child protection and children's rights. Children and Youth Services Review, 31(6), 601-608.

Miller, A. B., \& Cross, T. (2006). Ethnicity in child maltreatment research: A replication of Behl et al.’s content analysis. Child Maltreatment, 11(1), 16-26.

Moher, D., Liberati, A., Tetzlaff, J., \& Altman, D. G., \& The PRISMA Group. (2009). Preferred Reporting Items for Systematic Reviews and Meta-Analyses: The PRISMA Statement. PLoS Med, 6(7), e1000097.

Nagata, T., Kaye, W. H., Kiriike, N., Rao, R., McConaha, C., \& Plotnicov, K. H. (2001). Physical and sexual abuse histories in patients with eating disorders: A comparison of Japanese and American patients. Psychiatry and Clinical Neurosciences, 55(4), 333-340.

Nesci, A. (2006). Overcoming barriers to providing domestic violence services for women from culturally and linguistically diverse backgrounds. Parity, 19(2), 44.

O’Hagan. (1999). Culture, cultural identity, and cultural sensitivity in child and family social work. Child \& Family Social Work, 4(4), 269-281.

Owusu-Bempah, K., \& Howitt, D. (2000). Psychology beyond Western perspectives: London: Wiley-Blackwell.

Pasura, D., Jones, A. D., Hafner, J. A. H., Maharaj, P. E., Nathaniel-DeCaires, K., \& Johnson, E. J. (2013).

Competing meanings of childhood and the social construction of child sexual abuse in the Caribbean.

Childhood, 20(2), 200-214. 
Pereda, N., Guilera, G., Forns, M., \& Gomez-Benito, J. (2009). The international epidemiology of child sexual abuse: A continuation of Finkelhor (1994). Child Abuse and Neglect, 33(6), 331-342.

Petty, R. E., Wegener, D. T., Fabrigar, L. R., Priester, J. R., \& Cacioppo, J. T. (1993). Conceptual and methodological issues in the elaboration-likelihood model of persuasion: A reply to the Michigan State critics. Communication Theory, 3, 336-363.

Phasha, T. N. (2010). Educational resilience among African survivors of child sexual abuse in South Africa. Journal of Black Studies, 40(6), 1234-1253.

Pittaway, E., \& Rees, S. (2005-06). Multiple jeopardy: Domestic violence and the notion of cumulative risk for women in refugee camps. Women Against Violence: An Australian Feminist Journal, 18, 18-25.

Race, T. (1999). Hide and seek. Community Care, 19 August, 1286, 25.

Rao, K., DiClemente, R. J., \& Ponton, L. E. (1992). Child sexual abuse of Asians compared with other populations. Journal of the American Academy of Child and Adolescent Psychiatry, 31, 880-886.

Reavey, P., Ahmed, B., \& Majumdar, A. (2006). 'How can we help when she won't tell us what's wrong?' Professionals working with South Asian women who have experienced sexual abuse. Journal of Community \& Applied Social Psychology, 16(3), 171-188.

Reid, S. D., Reddock, R., \& Nickenig, T. (2014). Breaking the silence of child sexual abuse in the Caribbean: A community-based action research intervention model. Journal of Child Sexual Abuse, 23(3), 256-277.

Richter, L., Komárek, A., Desmond, C., Celentano, D., Morin, S., Sweat, M...\& Coates, T. (2014). Reported physical and sexual abuse in childhood and adult HIV risk behaviour in three African countries: Findings from Project Accept (HPTN-043). AIDS and Behavior, 18(2), 381-389.

Russell, D. E. H. (1986). The incest legacy. Sciences, 26, 28-32.

Royal Commission into Institutional Responses to Child Sexual Abuse, Working Definitions.

Samms, K. M., \& Cholewa, B. E. (2014). Exploring the context of child sexual abuse in Jamaica: Addressing the deficits. Journal of Child Sexual Abuse, 23(2), 115-127. 
Santos-Iglesias, P., \& Sierra, J. C. (2012). Sexual victimization among Spanish college women and risk factors for sexual revictimization. Journal of Interpersonal Violence, 27(17), 3468-3485.

Sawrikar, P. (2017). Working effectively with ethnic minorities and across cultures in Western child protection systems. UK: Routledge.

Sawrikar, P. (2015). How effective do families of non-English-speaking background (NESB) and child protection caseworkers in Australia see the use of interpreters? A qualitative study to help inform good practice principles. Child \& Family Social Work, 20(4), 396-406.

Sawrikar, P. (2013). A qualitative study on the pros and cons of ethnically matching culturally and linguistically diverse client families and child protection caseworkers. Children and Youth Services Review, 35(2), 321-331.

Sawrikar, P. \& Katz, I. (2010). “Only White people can be racist”: What does power have to do with prejudice? Cosmopolitan Civil Societies, 2(1), 80-99.

Sawrikar, P. \& Katz, I. (2009). How useful is the term "Culturally And Linguistically Diverse (CALD)" in the Australian social policy discourse? Refereed Conference Paper, Australian Social Policy Conference (ASPC) 2009.

Sawrikar, P. \& Katz, I. (2008). Enhancing family and relationship service accessibility and delivery to culturally and linguistically diverse (CALD) families in Australia, Issues paper prepared for the Australian Family Relationships Clearinghouse (AFRC), Issues No. 3.

Sawrikar, P., \& Hunt, C. J. (2005). The Relationship Between Mental Health, Cultural Identity and Cultural Values in Non-English Speaking Background (NESB) Australian Adolescents. Behaviour Change, 22(2), 97113.

Schrader, E. M., \& Wendland, J. M. (2012). Music therapy programming at an aftercare center in Cambodia for survivors of child sexual exploitation and rape and their caregivers. Social Work \& Christianity, 39(4), 390-406. Singh, A. A. (2009). Helping South Asian immigrant women use resilience strategies in healing from sexual abuse: A call for a culturally relevant model. Women \& Therapy, 32(4), 361-376.

Sil, K. H., \& Soo, K. H. (2008). Intra-familial sexual abuse (incest) among Korean adolescents Family Relations: 21st Century Issues and Challenges (pp. 71-86). 
Smith, K., Bryant-Davis, T., Tillman, S., \& Marks, A. (2010). Stifled voices: Barriers to help-seeking behavior for South African childhood sexual assault survivors. Journal of Child Sexual Abuse, 19(3), 255-274.

Smyth, M. (2002). Culture and society: The role of creativity in healing and recovering one's power and victimization. In J. P. Sutton (Ed.), Music, music therapy and trauma: International perspectives (pp. 57-81). London, UK and Philadelphia, PA: Jessica Kingsley Publishers.

Sossou, M-A., \& Yogtiba, J. A. (2009). Abuse of children in West Africa: Implications for social work education and practice. The British Journal of Social Work, 39(7), 1218-1234.

Stevenson, J. (1999). The treatment of the long-term sequelae of child abuse. Journal of Child Psychology and Psychiatry, 40, 89-111.

Stewart, S. (2005). Suicidality, interpersonal trauma and cultural diversity: A review of the literature. Australian e-Journal for the Advancement of Mental Health (AeJAMH), 4(2), 21p.

Sullivan, M., Bhuyan, R., Senturia, K., Shiu-Thornton, S., \& Ciske, S. (2005). Participatory action research in practice: A case study in addressing domestic violence in nine cultural communities. Journal of Interpersonal Violence, 20(8), 977-995.

Tajfel, H., \& Turner, J. C. (1979). The social psychology of intergroup relations. Brooks-Cole: Brooks-Cole.

Tang, S. (2009). Social context in traumatic stress: Gender, ethnicity, and betrayal (Doctoral dissertation).

Retrieved from http://dynamic.uoregon.edu/emeriti.html

Takeuchi, D. T., Sue, S., \& Yeh, M. (1995). Return rates and outcomes from ethnicity-specific mental health programs in Los Angeles. American Journal of Public Health, 85, 638-643.

Taylor, N., \& Putt, J. (2007). Adult sexual violence in Indigenous and culturally and linguistically diverse communities in Australia. Canberra: Australian Institute of Criminology.

Taylor, S., \& Norma, C. (2013). The ties that bind: Family barriers for adult women seeking to report childhood sexual assault in Australia. Women's Studies International Forum, 37, 114-124.

Tervalon, M., \& Murray-García, J. (1998). Cultural humility versus cultural competence: A critical distinction in defining physician training outcomes in multicultural education. Journal of Health Care of the Poor and Underserved, 9, 117-125. 
Thiara, R., Roy, S., \& Ng, P. (2015). Between the lines: Service responses to Black and Minority Ethnic (BME) women and girls experiencing sexual violence - Research Briefing. (pp. 1-9). UK.

Thoburn, J., Chand, A., \& Procter, J. (2005). Child welfare services for minority ethnic families: The research reviewed. Jessica Kingsley: London.

Thornton, C. P., \& Veenema, T. G. (2015). Children seeking refuge: A review of the escalating humanitarian crisis of child sexual abuse and HIV/AIDS in Latin America. JANAC: Journal of the Association of Nurses in AIDS Care, 26(4), 432-442.

Tishelman, A. C., \& Geffner, R. (2010). Introduction: Forensic, cultural, and systems issues in child sexual abuse cases - Part 2: Research and practitioner issues. Journal of Child Sexual Abuse, 19(6), 609-617.

Triandis, H. C. (1990). Theoretical concepts that are applicable to the analysis of ethnocentricism. In R. W. Brislin (Ed.), Applied cross-cultural psychology. New York: Sage.

Tutken, H. (1996). The frequency of dissociative disorders and childhood traumas in a general psychiatry ward. Unpublished doctoral dissertation, Istanbul University, Faculty of Medicine, Psychiatry Department.

Ullman, S. E., \& Filipas, H. H. (2005). Ethnicity and child sexual abuse experiences of female college students. Journal of Child Sexual Abuse, 14(3), 67-89.

Usta, J., \& Farver, J. (2010). Child sexual abuse in Lebanon during war and peace. Child: Care, Health and Development, 36(3), 361-368.

Wang, Y-W., \& Heppner, P. (2011). A qualitative study of childhood sexual abuse survivors in Taiwan: Toward a transactional and ecological model of coping. Journal of Counseling Psychology, 58(3), 393-409.

Weierich, M. R., \& Nock, M. K. (2008). Posttraumatic stress symptoms mediate the relation between childhood sexual abuse and nonsuicidal self-injury. Journal of Consulting and Clinical Psychology, 76(1), 39-44.

Welbourne, P. (2002). Culture, children's rights and child protection. Child Abuse Review, 11(6), 345-358.

Worku, D., Gebremariam, A., \& Jayalakshmi, S. (2006). Child sexual abuse and its outcomes among high school students in southwest Ethiopia. Trop Doct, 36, 137-40 
Zhang, T. H., Chow, A., Wang, L. L., Yu, J. H., Dai, Y. F., Lu, X...\& Xiao, Z. P. (2013). Childhood maltreatment profile in a clinical population in China: A further analysis with existing data of an epidemiologic survey. Comprehensive Psychiatry, 54(7), 856-864. 
Appendix: Summary of articles obtained from the PRISMA process examining barriers to help-seeking (RQ1), mental ill-health (RQ2), and treatment needs (RQ3) of ethnic minority victims/survivors of CSA

\begin{tabular}{l|l|l|l}
\hline REFERENCE & COUNTRIES/GRPS & RQs & METHODOLOGY/SAMPLE \\
\hline
\end{tabular}

\begin{tabular}{|c|c|c|c|}
\hline \multicolumn{4}{|l|}{ About ethnic minorities in Western countries } \\
\hline $\begin{array}{l}\text { 1. Back, Jackson, Fitzgerald, Shaffer, } \\
\text { Salstrom, and Osman (2003) }\end{array}$ & USA, Singapore & 2 & $\begin{array}{l}\text { Quantitative questionnaires } \\
(\mathrm{n}=153)\end{array}$ \\
\hline 2. Barker-Collo Read, and Cowie (2012) & Canada, New Zealand & 2 & $\begin{array}{l}\text { Quantitative questionnaire } \\
(n=290)\end{array}$ \\
\hline 3. Futa, Hsu, and Hansen (2001) & USA (East Asians) & 1,3 & Literature review \\
\hline 4. Fontes and Plummer (2010) & USA (various) & 1,3 & Literature review \\
\hline 5. Foynes, Platt, Hall, and Freyd (2014) & USA (East Asians) & 1 & Quantitative surveys $(n=266)$ \\
\hline 6. Gilligan and Akhtar (2006) & UK (South Asians) & 1,3 & Qualitative consultations \\
\hline 7. Gilligan and Akhtar (2005) & UK (South Asians) & 1 & $\begin{array}{l}\text { Mixed methods ( } \mathrm{n}=29 \\
\text { questionnaire, } \mathrm{n}=7 \text { community } \\
\text { discussion groups, } \mathrm{n}=46 \\
\text { consultation event) }\end{array}$ \\
\hline 8. Haboush and Alyan (2013) & USA (Arabs) & 1,3 & Literature review \\
\hline 9. Kanukollu and Mahalingam (2011) & USA (South Asians) & 1,3 & Literature review \\
\hline 10. Kenny and McEachern (2000) & USA (South Asians) & 1,2 & Literature review \\
\hline 11. Stewart (2005) & Australia (various) & 3 & Literature review \\
\hline 12. Taylor and Norma (2013) & Australia (various) & 1 & $\begin{array}{l}\text { Qualitative survey data }(n=336) \\
\text { and interviews }(n=64)\end{array}$ \\
\hline 13. Thiara, Roy, and Ng (2015) & UK (various) & 1,3 & Literature review \\
\hline 14. Ullman and Filipas (2005) & $\begin{array}{l}\text { USA (Black, White, } \\
\text { Hispanic, Asians) }\end{array}$ & 1 & Quantitative surveys $(n=461)$ \\
\hline
\end{tabular}

\begin{tabular}{l}
\hline \begin{tabular}{l|l|l|l}
\hline About non-Western countries & \multicolumn{1}{l}{} \\
\hline 15. Ajzenstadt and Cavaglion (2005) & Israel & 1,3 & Qualitative \\
16. Alao and Molojwane (2008) & Botswana & 3 & Quantitative - secondary \\
& & & analysis of case file data
\end{tabular}
\end{tabular}


17. Capri (2013)

18. Chen, Dunne, and Han (2004)

19. Chien (2013)

20. Chitereka (2010)

21. Elbedour, Abu-Bader, Onwuegbuzie, Abu-Rabia, and El-Aassam (2006)

22. Gibson, Emeka, and Walters (2007)

23. Haj-Yahia and Tamish (2001)

24. Karthiga and Ravikumar (2014)

25. Lev-Wiesel and Amir (2005)

26. Lev-Wiesel (2000)

27. Li, Ahmed, and Zabin (2012)

28. Ma and Li (2014)

29. Masehela and Pillay (2014)

30. Mathews, Abrahams, and Jewkes (2013)

31. Phasha (2010)

32. Samms and Cholewa (2014)

33. Schrader and Wendland (2012)

34. Sil and Soo (2008)

35. Smith, Bryant-Davis, Tillman, and Marks (2010)

\begin{tabular}{|c|c|c|}
\hline South Africa & $1,2,3$ & $\begin{array}{l}\text { Qualitative observations and } \\
\text { interviews }(n=4)\end{array}$ \\
\hline China & 2 & $\begin{array}{l}\text { Quantitative questionnaire } \\
(\mathrm{n}=2,300)\end{array}$ \\
\hline China & 1,3 & Delphi method $(\mathrm{n}=15)$ \\
\hline Zimbabwe & 1,3 & Literature review \\
\hline Israel & 1 & Quantitative surveys $(n=217)$ \\
\hline Jamaica & 2 & Literature review \\
\hline Palestine & 2 & Quantitative surveys $(n=652)$ \\
\hline India & 2 & $\begin{array}{l}\text { Quantitative questionnaire } \\
(\mathrm{n}=100)\end{array}$ \\
\hline Israel & 2 & Qualitative interviews $(n=22)$ \\
\hline Israel & 2 & Qualitative interviews $(\mathrm{n}=52)$ \\
\hline Taiwan & 2 & $\begin{array}{l}\text { Quantitative questionnaires } \\
(n=4,084)\end{array}$ \\
\hline Hong Kong & 2 & $\begin{array}{l}\text { Quantitative questionnaires } \\
(n=366)\end{array}$ \\
\hline South Africa & 1 & Qualitative interviews $(n=6)$ \\
\hline South Africa & 2,3 & Qualitative interviews $(\mathrm{n}=30)$ \\
\hline South Africa & 2 & Qualitative interviews $(n=22)$ \\
\hline Jamaica & 2,3 & Literature review \\
\hline Cambodia & 2,3 & $\begin{array}{l}\text { Mixed methods ( } \mathrm{n}=400 \text { case } \\
\text { file reviews, program } \\
\text { evaluation) }\end{array}$ \\
\hline Korea & $1,2,3$ & $\begin{array}{l}\text { Literature review and case } \\
\text { studies }(n=2)\end{array}$ \\
\hline South Africa & $1,2,3$ & Literature review \\
\hline
\end{tabular}


36. Sossou and Yogtiba (2009)

37. Wang and Heppner (2011)

\begin{tabular}{l|l|l} 
West Africa (Ghana, & 3 & Literature review \\
Nigeria, Togo) & & \\
Taiwan & 2,3 & Qualitative interviews (n=10)
\end{tabular}

